\title{
FLIGHT TESTS OF A SUPERSONIC NATURAL LAMINAR FLOW AIRFOIL
}

\author{
M.A. FREDERICK ${ }^{1, \mathrm{c}}$, D.W. BANKS ${ }^{1}$, G.A. GARZON² ${ }^{2}$ J.R. MATISHECK ${ }^{2}$ \\ ${ }^{1}$ NASA Armstrong Flight Research Center, Edwards, California, 93523, USA \\ ${ }^{2}$ Aerion Corporation, Reno, Nevada, 89502, USA \\ ${ }^{\mathrm{c} C}$ Corresponding author: Tel.: +16612762274; Fax: +16612762842; Email: mike.frederick-1@nasa.gov
}

KEYWORDS:

Main subjects: supersonic natural laminar flow, boundary layer transition

Fluid: boundary layer, laminar flow

Visualization method(s): infrared thermography

Other keywords: flight test, airfoil

\begin{abstract}
A flight test campaign of a supersonic natural laminar flow airfoil has been recently completed. The test surface was an 80-inch $(203 \mathrm{~cm})$ chord and 40-inch $(102 \mathrm{~cm})$ span article mounted on the centerline store location of an F-15B airplane. The wing was designed with a leading edge sweep of effectively 0 deg to minimize boundary layer crossflow. The test article surface was coated with an insulating material to avoid significant heat transfer to and from the test article structure to maintain a quasi-adiabatic wall. An aircraft-mounted infrared camera system was used to determine boundary layer transition and the extent of laminar flow. The tests were flown up to Mach 2.0 and chord Reynolds numbers in excess of 30 million. The objectives of the tests were to determine the extent of laminar flow at high Reynolds numbers and to determine the sensitivity of the flow to disturbances. Both discrete (trip dots) and 2-D disturbances (forward-facing steps) were tested. A series of oblique shocks, of yet unknown origin, appeared on the surface, which generated sufficient crossflow to affect transition. Despite the unwanted crossflow, the airfoil performed well. The results indicate the sensitivity of the flow to the disturbances, which can translate into manufacturing tolerances, were similar to that of subsonic natural laminar flow wings.
\end{abstract}




\section{Introduction}

A current goal for the National Aeronautics and Space Administration [NASA] is to eliminate barriers that prevent the development of practical supersonic cruise vehicles. One of the research thrusts related to this goal is the development of technologies to increase the cruise efficiency of high-speed airframes. Drag reduction through the use of natural laminar flow [NLF] is one area that is currently being investigated for efficiency improvements. Conventional supersonic designs feature highly swept wings with subsonic leading edges to minimize inviscid drag [1]. The large sweep angle generates a spanwise pressure gradient that leads to three-dimensionality in the boundary layer, while the use of a subsonic leading edge typically results in a wing design with a large leading edge radius and thick foil sections that create an adverse streamwise pressure gradient. A drawback of this type of wing design is that it exacerbates several different boundary layer instability mechanisms, the end result being a wing with low inviscid drag but little to no natural laminar flow.

There are four primary instability mechanisms associated with swept wings: attachment-line, streamwise, crossflow, and centrifugal. Attachment-line contamination can occur on swept wings with large leading edge radii. This form of instability causes transition at the leading edge if the attachment-line Reynolds number exceeds a critical value that is dependent on the initial flow condition (laminar or turbulent) at the wing root junction. The streamwise instability is caused by the linear amplification of disturbances, referred to as Tollmien-Schlichting waves, which propagate in the boundary layer parallel to the wall. Tollmien-Schlichting waves are amplified by an adverse pressure gradient, which is common on conventional high-speed designs. The crossflow instability is an inflectional instability and is the dominant form of instability for wings with moderate to high sweep (sweep angles greater than approximately $25 \mathrm{deg}$ ). Swept wings can generate a significant spanwise pressure gradient on the wing. This pressure gradient results in the formation of a velocity component in the boundary layer or crossflow that is perpendicular to the inviscid streamline. The crossflow velocity component must be zero both at the wall and at the edge of the boundary layer, resulting in an inflection point in the boundary layer velocity profile. This inflection point is a source of instability that occurs as a pair of co-rotating vortices whose axes are aligned within a few degrees of the local inviscid streamlines [2]. The centrifugal instability, commonly referred to as Görtler instability, is associated with surface concavity and results in the formation of counterrotating vortices that are destabilizing to the boundary layer. This mode of instability can be controlled through configuration design. A more thorough description of these four transition mechanisms can be found in [3], while a detailed review of boundary layer stability theory and transition in general can be found in [4-6].

One method that is currently being investigated to improve the efficiency of high-speed airframes is viscous drag reduction through the use of natural laminar flow. Compressibility acts to stabilize the boundary layer at supersonic speeds, making it possible to obtain significant runs of supersonic natural laminar flow if configuration changes that suppress the different boundary layer instability mechanisms are incorporated into the airframe design. Increased range, lower fuel burn, and lower aircraft weight are all benefits that could be achieved by increasing the amount of laminar flow on an airplane. For a 110,000-lb (49,895 kg) class corporate jet with a cruise Mach of 1.5, increasing the amount of laminar flow on the wing from the typical 5 percent to 80 percent could result in an increase in range of approximately 48 percent [7].

The Aerion Corporation (Reno, Nevada, USA) has developed a design for a supersonic business jet $[\mathrm{SBJ}]$ that features a wing optimized for natural laminar flow [8-10]. The Aerion SBJ has a design range in excess of $4000 \mathrm{~nm}(7408 \mathrm{~km})$. To meet this goal, the wing must maintain laminar flow for 
transition Reynolds numbers on the order of 30 million. The wing design features a sharp leading edge, a low-sweep angle, and thin foil sections shaped to produce a favorable streamwise pressure gradient on both the upper and lower wing surfaces. The sharp leading edge eliminates the possibility of attachment-line transition while the favorable streamwise pressure gradient helps suppress Tollmien-Schlichting instabilities in the boundary layer. A major benefit of the low-sweep angle is a reduction in spanwise pressure gradients that lead to crossflow instabilities in the boundary layer. Another benefit is improved aerodynamic performance in the subsonic regime. One drawback of using a low-sweep angle is that, at supersonic speeds, the flow component normal to the leading edge is supersonic, resulting in an increase in wave drag. The sharp leading edge and thin foil sections featured in the Aerion design help offset the wave drag increase due to the low-sweep angle.

NASA and the Aerion Corporation have teamed together to study supersonic natural laminar flow and boundary layer transition through a series of joint flight tests using an F-15B (McDonnell Douglas Corporation, now The Boeing Company, St. Louis, Missouri, USA) NASA research test bed airplane, shown in figure 1, dating back to 1999. In the first series of tests, referred to as the Supersonic Natural Laminar Flow [SSNLF] project, a small-chord biconvex test article was mounted on the centerline pylon of the F-15B airplane and flown out to a free-stream Mach number of 1.8. Images of the boundary layer transition were obtained from an analog infrared [IR] imaging system mounted on the forward starboard armament rail of the F-15B airplane. The SSNLF test article included an insulative coating material to minimize heat conduction to the aluminum substructure. Results from the SSNLF project demonstrated the feasibility of maintaining large runs of laminar flow on low-swept wings at chord Reynolds numbers up to 10 million [11,12]. An IR image obtained from one of the SSNLF flights is shown in figure 2. In this figure, the flow direction is from right to left, and the laminar portion of the boundary layer appears dark while the turbulent portion appears light.

The Supersonic Boundary Layer Transition [SBLT] project followed the SSNLF testing with the objective of expanding the results from SSNLF to more complex surfaces with larger chord lengths (higher chord Reynolds numbers). A multi-purpose support structure, or "strong back," was fabricated from 6061 aluminum for testing large chord test articles on the NASA F-15B airplane using a modified centerline pylon referred to as the Centerline Instrumented Pylon [CLIP]. The strong back design allows for test articles to be bolted onto the right-hand side (test side) of the strong back. The left-hand side (non-test side) of the strong back includes an instrumentation bay and five conical probe mounts with 7.5 -inch $(19 \mathrm{~cm})$ spanwise spacing located near the leading edge.

The SBLT project was comprised of two phases. Phase 1, flown in 2010, involved flight-testing a flat-plate test article underneath the F-15B airplane out to a free-stream Mach number of 2.0 [13]. The primary objective of this test was to quantify the local flow field underneath the F-15B at the flat-plate test article location. The flat-plate test article, which was bolted to the right-hand side of the strong back, had an 84-inch $(213 \mathrm{~cm})$ chord and a 41 -inch $(104 \mathrm{~cm})$ span with a leading edge sweep of approximately $10 \mathrm{deg}$. An array of 60 surface pressure ports was used to measure the pressure on the test surface. On the strong back, five 5-hole conical probes were mounted near the leading edge at 7.5-inch intervals along the span for measurement of the inflow velocity and direction. The probes were mounted approximately 3 inches $(7.6 \mathrm{~cm})$ to the left of the leading edge to ensure that the shocks from the probes did not contaminate the test surface and that the leading edge shock from the plate would not contaminate the probe measurements. Surface pressures, local inflow measurements, and IR thermography images were obtained out to chord Reynolds numbers in excess of 26 million. Figures 3(a) and 3(b) show local flow measurements and an IR image from the flat-plate test article at Mach 1.57. The flow direction in both figures is from right to left. 
The surface pressure measurements from the flat-plate test article were used to aid in the design of an NLF article for a second phase of flight tests. In 2013, the NLF test article, hereafter referred to as the test article, was flown on the bottom centerline location of the F-15B airplane using the CLIP and strong back previously used for phase 1 . The objectives of phase 2 were to determine the extent of laminar flow on the test article at supersonic speeds and high Reynolds numbers, to determine the stability of the laminar flow with varying Reynolds number, and to determine the sensitivity of the boundary layer to various discreet (trip dots) and 2-D (forward-facing steps) disturbances. The results from this second phase of flight-testing are the focus of this paper.

\section{Methodology and Approach}

The F-15B airplane is a two-seat fighter and trainer version of the F-15A high-performance, supersonic air-superiority fighter (both built by McDonnell Douglas Corporation, now The Boeing Company, St. Louis, Missouri) and is powered by twin F100-PW-100 afterburning turbofan engines (Pratt \& Whitney, West Palm Beach, Florida). The NASA F-15B airplane has been converted from a United States Air Force air-superiority fighter to a research test bed airplane. Research instrumentation, recording, telemetry, and video systems have been installed on the airplane. A calibrated National Advisory Committee for Aeronautics [NACA] -style flight-test nose boom was installed on the airplane and used for measurements of free-stream Mach number, angle of attack, and angle of sideslip. A research total temperature probe, installed on the bottom side of the forward fuselage of the airplane, was used for measurement of the free-stream total temperature. The total temperature and free-stream Mach number measurements were used to derive the static temperature, density, and unit Reynolds number of the free-stream flow.

The digital IR sensing system on the NASA F-15B airplane is comprised of an IR camera, a camera pod, and analog and digital recording systems. The IR camera utilizes an indium antimonide (InSb) $640 \times 512$ focal plane array with a 28 -micron pitch. The camera is sensitive in the mid-infrared spectrum of 3 to 5 microns. The camera was fitted with a 13-mm lens to capture the entire test article while minimizing the amount of background captured. A streamlined camera pod was designed to house the camera. The camera pod mounts on the forward starboard armament rail of the F-15B airplane adjacent to the \#2 engine inlet, as shown in figure 4. A silicon window with an antireflection coating optimized for the 3 to 5 micron spectral range was installed on the inner surface of the camera pod. Inside the camera pod, a right-angle prism was mounted adjacent to the window to redirect the IR image toward the camera lens. The IR camera simultaneously outputs analog (RS-170) and 14-bit digital (high-speed serial interface) video at 30 frames per second. The analog video was recorded using an onboard analog $(8 \mathrm{~mm})$ tape recorder and was converted to DVD format post-flight. An onboard digital data recorder with approximately $2 \mathrm{hr}$ of recording time was used to record the digital output from the camera.

The phase 2 test article, shown in figure 5, had an 80-inch $(203 \mathrm{~cm})$ chord and a 40 -inch $(102 \mathrm{~cm})$ span. The test article had a sharp leading edge with a sweep angle of 0 deg in order to minimize crossflow for the majority of the test surface. A small section of the leading edge near the tip included a radius (curved planform) to purposefully induce crossflow in that region and to prevent the formation of a tip shock that could spread across the test article. The test article was cambered with a maximum thickness to chord ratio of 6.9 percent and was manufactured from 6061 aluminum coated with an epoxy that was machined to produce a smooth surface finish. The epoxy was added to insulate the test surface from the aluminum substructure in order to provide quasi-adiabatic conditions at the test surface. A thin layer of black matte paint was applied over the epoxy to minimize reflections on the test surface. The total weight of the test article was approximately $930 \mathrm{lb}$. 
Four Resistance Temperature Detectors [RTDs] were mounted on the test surface for measurement of the surface temperature. The sensors were located along the bottom and the trailing edges of the test article, where the boundary layer was expected to be turbulent, to ensure they would not cause transition. The locations of the sensors are shown in figure 5. Surface pressure measurements were not included on the test article for fear of introducing disturbances that could cause premature transition of the boundary layer. Four of the five conical probes used during phase 1 were installed on the strong back. The forward locations of the probe mounts on the strong back had been designed to place the tips of the probes adjacent to the leading edge of the phase 1 flat-plate test article, which had a leading edge sweep angle of approximately $10 \mathrm{deg}$ and a leading edge root location close to 1 inch $(2.54 \mathrm{~cm})$ downstream of the phase 2 test article leading edge root location. These two geometric differences resulted in all of the phase 1 conical probes, when installed on the strong back, being located behind the phase 2 test article leading edge. Given their location behind the test article leading edge, the measurements from the four phase 1 probes were not expected to be reliable. In order to collect inflow measurements at the mid-span of the test article leading edge, an alternate five-hole conical probe (phase 2) with a longer body than the phase 1 probes was installed at the mid-span location on the strong back. A new probe holder was designed to allow the alternate probe to be installed with its apex adjacent to the test article leading edge. Pressure tubing from the probes was routed through channels in the strong back to pressure transducers installed in the strong back instrumentation bay. Figure 6 shows the locations of the alternate probe (labeled phase 2) and phase 1 probes on the strong back, as well as the instrumentation bay.

Trip dots and 2-D forward-facing steps were installed on the test article for several of the flights toward the end of the flight test series after sufficient baseline transition data had been obtained for the clean test article. The objective of these flights was to quantify the boundary layer sensitivity to disturbances that would be intrinsic to the manufacture and operation of a supersonic cruise airplane (for example, insect contamination and manufacturing tolerances). The trip dots were made from various types of adhesive tapes with heights of 2,3 , and $4.5 \mathrm{mil}(0.051,0.076$, and $0.114 \mathrm{~mm})$. A 3/16-inch $(4.8 \mathrm{~mm})$ punching die and polyimide adhesive tape were used to make the 2-mil dots, whereas a 1/16-inch $(1.6 \mathrm{~mm})$ hole punch was used to make the 3-and 4.5-mil trip dots from aluminum tape. A total of 19 trip dots were applied to the test article. The trip dot layout incorporated spanwise and chordwise spacing to ensure that transition wedges could be differentiated while testing different chord Reynolds numbers. Figure 7(a) shows the leading edge of the test article with the layout for the trip dots, which are highlighted in red. Adhesive backed vinyl film, typically used for wrapping automobiles, was used to create the 2-D forward-facing steps. The film had a nominal thickness of 4.5 mil. Strips of the film approximately 30 -inches $(76 \mathrm{~cm})$ long were applied as a single 4.5 mil step and were also layered to create step heights of 13.5 and $22.5 \mathrm{mil}(0.343$ and $0.572 \mathrm{~mm})$. The top and bottom of the steps were tapered inwards toward the trailing edge to account for turbulent wedge formation from the corners of the forward face of the steps. The leading edge of the steps was located approximately 8.5 inches $(21.6 \mathrm{~cm})$ downstream of the test article leading edge. An upper and lower step, each with a different height, was applied to the test surface, as shown in figure 7(b); the outline of the steps is highlighted in blue. Thin strips of aluminum tape were placed near the leading edge corners of both steps and near the trailing edge of the upper step to provide a frame of reference for the IR images. Aluminum tape was chosen because it shows up well on IR images.

Supersonic boundary layer transition data were collected during 11 flights. Data were collected up to Mach 2.0 and unit Reynolds numbers up to $\mathrm{Re}_{\mathrm{ft}}=4.6 \mathrm{million} / \mathrm{ft}(1.4 \mathrm{million} / \mathrm{m})$, which equates to a chord Reynolds number $\mathrm{Re}=30.7$ million. The majority of the test data were collected at Mach 1.7, as this provided a local Mach number that was close to the test article design Mach number. Transition data were collected during each flight using one of two different profiles. Profile 1 consisted of a straight-and-level acceleration out to the maximum Mach number at a nominal 
altitude of $42,000 \mathrm{ft}(12,802 \mathrm{~m})$. At the end of the acceleration, a short steady-state point was obtained at the maximum Mach number followed by a straight-and-level deceleration back to subsonic conditions. Profile 2 consisted of a straight-and-level acceleration at $42,000 \mathrm{ft}$ out to a nominal Mach number of 1.3, a constant Mach ascent to 49,500 ft $(15,088 \mathrm{~m})$, and a straight-andlevel acceleration from Mach 1.3 to the maximum Mach number, typically Mach 1.7. At the end of the acceleration, a short steady-state point was obtained at the maximum Mach number followed by a nominally constant Mach descent down to a target altitude. The target altitude during the descent was dependent upon the maximum dynamic pressure desired for each individual flight, but was limited to no lower than $30,000 \mathrm{ft}(9,144 \mathrm{~m})$ or a maximum dynamic pressure of $1200 \mathrm{psf}$ $(57.5 \mathrm{kPa})$ while supersonic. The constant Mach descent provided transition data at the test Mach number for a range of Reynolds numbers.

Infrared thermography images from the camera analog output were telemetered in real time to the control room and were also recorded onboard using the analog recorder. The analog images received processing to enhance contrast using algorithms proprietary to the camera manufacturer prior to being output into the telemetry and recording streams. The digital images underwent minimal processing by the camera and were recorded onboard using the digital data recorder. Both analog and digital images were analyzed post flight; however, the results presented in this paper focus on the analog images as they more clearly show the flow features when compared to the minimally-processed digital data. In the future, the digital data will be used along with the RTD measurements for temperature mapping of the test article surface.

Due to the camera position on the armament rail (forward, above, and to the side of the test article) and due to the wide-angle lens used in the camera, there was considerable distortion in the IR images. A frame of the analog IR from flight 452 showing this distortion is presented in figure 8 . In this image and all subsequent IR images presented in this paper, the flow direction is from right to left. The analog images were transformed into a side-facing perspective post-flight for analysis purposes. In order to perform the image transformation, a calibration grid was created using strips of 0.5 -inch $(1.27 \mathrm{~cm})$-wide aluminum tape applied vertically and horizontally to the test article surface. A small amount of IR video of the test article with the calibration grid was recorded and photographs of the calibration grid were taken from the desired perspective for the transformation. A frame from the analog IR video and a photo of the calibration grid are shown in figures 9(a) and 9(b), respectively. The images from figures 9(a) and 9(b) were loaded into commercially-available imaging processing software and a total of 127 control points pairs were located on each figure using the calibration grid. A fourth-order polynomial transform was generated from the control point pairs and was applied to the analog image to spatially transform the image into the desired perspective. The transform was applied frame-by-frame to the IR videos post-flight for analysis purposes.

The spatial transformation of the IR image from figure 8 is shown in figure 10. The image has been cropped to minimize unnecessary background clutter. Selected flight parameters appear as text near the top of the image, and significant flow phenomenon have been labeled. The transformation has removed the majority of the distortion and rotated the image into a side-facing perspective, allowing for more accurate determination of the extent of laminar flow. The image clearly shows the laminarturbulent transition boundary. At this flight condition, laminar regions appear dark while turbulent regions appear light. Areas where the transition line has a wispy, sawtooth pattern of turbulent wedges, as at the bottom of the test article, indicate transition due to crossflow. Portions of the transition line that exhibit a less-distinct sawtooth appearance are regions where transition is thought to be due to crossflow induced by weak oblique shocks. A turbulent wedge is located at the mid-span location. The wedge is somewhat faint and the apex location is hard to discern, indicating that the transition here is incipient or in its initial stage. The IR image also shows several shock waves impinging on the test surface. A shock emanating from the leading edge of the camera pod 
covers the entire span of the test article, and is located approximately mid-chord in the figure. The chordwise impingement location of this shock was observed to be a function of airplane Mach number.

As shown in figure 10, a series of weak oblique shocks parallel to one another, or a "shock train" are present across the span toward the front third of the test article. A close examination of the figure reveals at least six shocks. Only four of them stand out clearly in the IR image; these four shocks are identified in the figure. These shocks, hereafter referred to as train shocks, are undesirable, because they produce a spanwise pressure gradient, similar to a swept wing, which causes crossflow. The pressure rise through the shocks also creates an adverse streamwise pressure gradient that would exacerbate Tollmien-Schlichting instabilities. At higher Reynolds numbers, several of the individual train shocks caused premature transition on the test article. An example of this forced transition is shown in figure 10. The transition line in the area near one-third span marked "CF transition" has moved upstream compared to the laminar area directly above, and is coincident with the aft train shock indicating that the shock is forcing early transition.

The source of the train shocks is still under investigation. The shocks exhibit a small increase in sweep angle with Mach number suggesting that they are not being generated from any airplane structure that is located at a considerable distance from the test surface, such as the wing or inlet ramps. If the shocks were being generated from a considerable distance away from the test article, they would be expected to sweep back across the entire surface of the test article as the aircraft Mach number increases, similar to the behavior of the camera-pod shock. One hypothesis under investigation is that the shocks are being generated from the CLIP. Of particular interest is the splitter plate portion of the CLIP (figure 5). The flow underneath the airplane near the nose of the CLIP has a downward component. The splitter plate would be expected to turn the flow toward the fuselage, creating a shock wave when supersonic. This shock wave should propagate upward toward the fuselage and may then be reflected back toward the splitter plate and test article. It's possible that a series of shock reflections are occurring between the splitter plate and the fuselage, with the downward reflections wrapping around the splitter plate and impinging on the test article. If this were occurring, one would expect to have seen the train shocks during phase 1 testing of the flat-plate test article, as the airplane and CLIP configurations were the same for both phase 1 and phase 2 . The train shocks were not apparent on the phase 1 IR images; however, this may be due to the lack of insulation and the higher reflectivity of the phase 1 test article, which resulted in flow features being less distinguishable in the IR images. A few theories regarding the shock formation due to the test article shape have been postulated, but all have been deemed to be not credible. Ultimately, the source of these shocks requires further investigation.

\section{Results}

Data are presented for three of the eleven data flights, with the majority of data from flight 452 (flight 5 of 11). A few of the IR images from two of the roughness element flights (454 and 456) are presented to show the effects of roughness elements on transition. Profile 2, with a nominal maximum Mach number of 1.7, was flown on all three of these flights. A time history of aircraft pressure altitude and Mach number for the test portion of flight 452 is shown in figure 11. The F-15B airplane was accelerated out to Mach 1.7 at 49,500 ft followed by a constant Mach descent to approximately 33,000 ft $(10,058 \mathrm{~m})$. Small variations in Mach number occurred throughout the descent due to piloting tolerances. 


\subsection{Test Article Conditions with Mach Number}

Figure 12 shows the test article surface temperature measurements from the four RTDs during the test portion of flight 452 . The aircraft total temperature and an estimate of the turbulent adiabatic wall temperature are also included in the figure. The adiabatic wall temperature was estimated from equation 1 , where the recovery factor $r=0.88$ for a turbulent boundary layer [14].

$T_{a w}=T_{\infty}\left(1+r \frac{\gamma-1}{2} M_{\infty}^{2}\right)$

The temperature and Mach number terms on the right-hand side of equation 1 correspond to the temperature and Mach number at the edge of the boundary layer for each RTD location. As these quantities weren't measured in flight, free-stream values for $\mathrm{T}_{\infty}$ and $\mathrm{M}_{\infty}$ were used in equation 1 , with the understanding that this is not a rigorous use of the equation. The laminar adiabatic wall temperature was not estimated because the RTDs were located in regions where the boundary layer was known to be turbulent. As shown in figure 12, the four surface temperatures and the free-stream total temperature at the start of the acceleration maneuver were between -14 and $-20{ }^{\circ} \mathrm{F}$ $\left(-25.5\right.$ and $\left.-28.9^{\circ} \mathrm{C}\right)$. The adiabatic wall temperature was approximately $-28{ }^{\circ} \mathrm{F}\left(-33.3{ }^{\circ} \mathrm{C}\right)$. Three of the four surface temperature measurements were approximately $15^{\circ} \mathrm{F}$ greater than the adiabatic wall temperature from the start of the acceleration, indicating "hot wall" conditions. From Mach 1.22 out to Mach 1.7, the surface measurements were all less than the adiabatic wall temperature, indicating "cold wall" conditions where heat was being transferred to the test article through the boundary layer. The peak surface temperature was experienced at the end of the constant Mach descent and was approximately $133{ }^{\circ} \mathrm{F}\left(54.4{ }^{\circ} \mathrm{C}\right)$ at the RTD1 location (figure 5) while the free-stream total temperature was approximately $185^{\circ} \mathrm{F}\left(85^{\circ} \mathrm{C}\right)$. At this same flight condition, the lowest surface temperature was $121^{\circ} \mathrm{F}\left(49.4{ }^{\circ} \mathrm{C}\right)$ at the RTD4 location. The adiabatic wall temperature at this flight condition was $158^{\circ} \mathrm{F}\left(70{ }^{\circ} \mathrm{C}\right)$, which was $15^{\circ} \mathrm{F}$ greater than the highest temperature measured on the surface.

Figure 13 shows the local Mach number and flow angularity measured by the phase 2 probe installed mid-span on the strong back. The angle-of-attack and flank angle-of-attack values given in figure 13 are with respect to the test article. For example, positive angle of attack with respect to the test article is equivalent to negative flank angle of attack in the airplane reference frame, whereas positive flank angle of attack with respect to the test article is equivalent to positive angle of attack in the airplane reference frame. The abrupt change in local flow properties near the beginning and end of the profile was due to the passage of the camera-pod shock past the probe. At Mach numbers below approximately Mach 1.22 the camera-pod shock was in front of the test article leading edge, resulting in transonic conditions at the probe that were below the calibration range of the probe. After passage of the camera-pod shock, the flow at the test article was supersonic and the conical probe was within its functional calibration range. As shown in figure 13, the test article experienced a steady increase in angle of attack from approximately -1.0 to $1.1 \mathrm{deg}$ as the airplane accelerated out to Mach 1.7. The flank angle of attack during this time period varied from approximately 0 to -4.3 deg. At the test Mach number of Mach 1.7, the local Mach number at the test article was approximately Mach 1.65 .

\subsection{Transition Pattern with Mach Number}

On flight 452, an initial acceleration out to Mach 1.3 was performed at a nominal altitude of 42,000 $\mathrm{ft}$ before performing a constant Mach climb up to 49,500 ft. Figures 14-16 show the start of the acceleration from Mach 0.95 out to Mach 1.3. As a reminder, the flow direction in these and all subsequent IR figures in this paper is from right to left. Aerodynamic heating due to skin friction at 
these Mach numbers is low. The test article, still retaining some heat from the ground, is warmer than the adiabatic wall temperature. The laminar boundary layer acts as an insulator for the test article whereas the turbulent boundary layer, with its larger convective-heat transfer coefficient, transfers more heat to the atmosphere. As a result, the laminar region of the test article appears lighter than the turbulent portion in these three figures. Toward the upper portion of the test article, the laminar region extends beyond the 75 percent chord location. The small black dots on the test article are areas where the epoxy insulation had to be re-applied during manufacturing due to pitting. As the airplane accelerates to Mach 1.2, there is a very small increase in the extent of the laminar flow region on the test article. At Mach 1.3, the extent of laminar flow has not changed, but the intensity of the laminar region has begun to fade slightly.

At higher Mach numbers, the test article temperature increases, but at a slower rate than the adiabatic wall temperature. The test article becomes "cold" relative to the adiabatic wall temperature. The laminar boundary layer is now insulating the "cooler" surface while the turbulent boundary layer transfers more heat to the surface, resulting in the laminar regions now appearing darker and the turbulent regions appearing lighter in the IR images. Figure 17 shows an image captured at Mach 1.35 during the climb up to 49,500 $\mathrm{ft}$. The laminar region extends from the leading edge of the test article to approximately 7 percent chord near the root and 13 percent at the tip. The short extent of laminar flow is a result of forced transition from the camera-pod shock impinging upon the test article surface. The shock impingement location, located at the transition between the darker and lighter areas near the front of the test article, covers the entire span of the test article. A spurious turbulent wedge is also apparent near the outboard leading edge of the test article.

Figures 18-22 show the shape of the transition line at five different Mach numbers [1.4, 1.5, 1.55, 1.6, and 1.7] during the straight-and-level acceleration at 49,500 ft. At Mach 1.4, the camera-pod shock (the aft edge of the dark line) is forcing transition for the entire span. The transition line does, however, extend a few inches aft of the shock. The extent of laminar flow has increased because the shock has swept further aft due to the increase in Mach number. The transition line is now located at roughly 13 percent chord at the root and 22 percent chord at the tip. The spurious wedge near the tip of the test article has disappeared. Two white lines, located at roughly 65 percent chord, are shocks of a yet unknown origin. At Mach 1.5, transition for the entire span of the test article is no longer being forced by the camera-pod shock. On the inboard section of the test article, the laminar region extends slightly beyond the camera-pod shock location and is marked by a slight sawtooth appearance. Directly below this region, at approximately 25 percent span, a small portion of laminar flow extends to approximately 39 percent chord. Moving outboard, the transition line moves back toward the leading edge. A large percentage of the boundary layer in this region experiences forced transition due to the camera-pod shock. The boundary layer from the tip to approximately 5 inches $(12.7 \mathrm{~cm})$ inboard has transitioned upstream of the camera-pod shock. Crossflow induced from the tip geometry (radius) is responsible for the early onset of transition in this region.

A new phenomenon is apparent in the laminar region of the boundary layer at Mach 1.55, shown in figure 20. A series of parallel black lines swept back at approximately $30 \mathrm{deg}$ with respect to the leading edge are present on the front portion of the test article. These black lines are the shock train described previously in Section 2, "Methodology and Approach." The camera-pod shock appears as the furthest aft dark line located at the 25 percent chord location. The camera-pod shock and the last train shock intersect at approximately mid-span. The transition pattern is similar to that seen at Mach 1.5; however, the extent of laminar flow has increased as the camera-pod shock has moved aft. A long run of laminar flow at the one-third span location persists significantly aft of the camera-pod shock just past 75 percent chord. At these higher Mach numbers, the camera-pod shock impingement on the test article occurs at a more oblique angle due to the sweep back of the shock with Mach number. The shock, now more oblique than at lower Mach numbers, is weaker, allowing 
the laminar flow to persist beyond the impingement line. The extended run of laminar flow finally transitions just upstream of another shock impinging on the test article surface, shown as a bright white line.

At Mach 1.6, shown in figure 21, a significant portion of the transition line is located beyond the camera-pod shock. Between one-quarter and three-quarters span, a large portion of laminar flow persists out to approximately 75 percent chord. A turbulent wedge, originating just aft of the camera-pod shock, is located just inboard of the mid-span location. The transition line outboard of the large run of laminar flow has a wispy, sawtooth appearance indicative of crossflow and is located just aft of the camera-pod shock. The transition line in this region is located at roughly 44 percent chord, whereas the transition line near the tip is located at roughly 25 percent chord. The difference in transition line chord locations between these two regions suggests that the crossflow due to the tip radius is significantly stronger than the crossflow generated by the shock impingement.

The acceleration at 49,500 $\mathrm{ft}$ was terminated at Mach 1.7. The transition line for this Mach number is shown in figure 22. A small section of the inboard portion of the boundary layer has transitioned to turbulent slightly aft of the camera-pod shock just upstream of the 50 percent chord location. A large region of laminar flow is present between one-quarter and three-quarters span, extending slightly beyond 88 percent chord at mid-span. The turbulent wedge that existed in this region at Mach 1.6 has disappeared. The crossflow region near the test article tip has extended inboard several inches; however, the chord location of the transition line in this region is effectively the same as it was at lower Mach numbers. A few small areas of incipient transition appear as light streaks in the laminar region. One of these streaks is located aft of the last train shock at about one-third span. Four of the train shocks stand out very well in the IR image. The train shocks have swept back a small amount, as compared to their location at Mach 1.55, now making an angle of approximately $36 \mathrm{deg}$ with the leading edge. Another interesting change has taken place near the leading edge: The region from the leading edge up to roughly 6 percent chord now appears light instead of dark even though the flow is still laminar in this region. This is a result of the test article heating up disproportionately in this area. The thickness of the insulation goes to zero just downstream of the leading edge, and the thickness of the aluminum substructure also decreases toward the leading edge, resulting in a lower local thermal inertia in this region. The end result is a localized heating of the aluminum substructure near the leading edge.

\subsection{Reynolds Number Effects on Transition at Mach 1.7}

After the airplane reached Mach 1.7, a constant Mach descent was flown to approximately 33,000 ft to study the effects of Reynolds number on boundary layer transition for the Mach 1.7 condition. Images from the descent with unit Reynolds numbers of $\mathrm{Re}_{\mathrm{ft}}=2.67 \mathrm{million} / \mathrm{ft}(0.814 \mathrm{million} / \mathrm{m})$ and $\mathrm{Re}_{\mathrm{ft}}=3.49$ million/ $\mathrm{ft}(1.06$ million/m) are shown in figures 23 and 24 . A yellow line showing the transition pattern at the beginning of the descent at $\mathrm{Re}_{\mathrm{ft}}=2.14 \mathrm{million} / \mathrm{ft}(0.652 \mathrm{million} / \mathrm{m})$ from figure 22 has been added to both figures for comparison purposes. At $\mathrm{Re}_{\mathrm{ft}}=2.67 \mathrm{million} / \mathrm{ft}$ (figure 23) the laminar flow no longer extends beyond the camera-pod shock. The largest extent of laminar flow is approximately 56 percent chord at the three-quarters span location. The aft train shock appears to be forcing transition in the region of one-third to mid-span. The transition line in this region has the familiar wispy, sawtooth appearance indicative of crossflow transition. A small wedge indicating incipient transition is present behind the second train shock.

At $\mathrm{Re}_{\mathrm{ft}}=3.49 \mathrm{million} / \mathrm{ft}$ (figure 24) the camera-pod shock is no longer forcing transition on the test article. The train shocks appear to be forcing transition for a large portion of the span. The transition line has moved almost entirely forward of the 25 percent chord line, and is characterized by a wispy, sawtooth pattern in the inboard and outboard regions, and a more jagged pattern with a few distinct wedges mid-span. The furthest extent of laminar flow is near the upper portion of the test 
article. The transition line in this region is coincident with the fourth train shock. The aft two train shocks, labeled in figure 24, appear as white lines now that the flow on the majority of the test article is turbulent. The transition line in the mid-span region is located directly in between the first and second train shocks. The transition region near the tip has moved upstream and is now located at approximately 19 percent chord.

\subsection{Roughness Elements Effects on Transition at Mach 1.7}

Transition patterns for the trip dots from flight 454 are shown in figures 25-27. A yellow line showing the transition line for the clean test article from flight 452 at similar Reynolds numbers (figures 22-24) has been added to the figures for comparison. The locations of the trip dots have been highlighted in red on these figures as well. The beginning of the Mach 1.7 descent at $\mathrm{Re}_{\mathrm{ft}}=2.21 \mathrm{million} / \mathrm{ft}(0.674 \mathrm{million} / \mathrm{m})$ is shown in figure 25 . At this condition, the majority of the trip dots have not yet caused transition. Two turbulent wedges are located about mid-span. The growth of these wedges has eliminated the large extent of laminar flow that existed on the clean test article at this Reynolds number. The apex of the top wedge is located directly upstream of the second train shock, and has a faint appearance until it has passed the shock. Incipient transition starts upstream of the shock and looks to be caused by a 4.5-mil trip dot located approximately 6 inches $(15.24 \mathrm{~cm})$ downstream of the leading edge. The second train shock appears to accelerate transition from this dot. The lower turbulent wedge shows incipient transition originating from a 2-mil trip dot that was located approximately 1.375 inches $(3.49 \mathrm{~cm})$ from the leading edge. It appears that the first train shock may be accelerating the transition of this wedge. Figure 26 shows the transition pattern for $\mathrm{Re}_{\mathrm{ft}}=2.67 \mathrm{million} / \mathrm{ft}$. The apex of the first turbulent wedge has moved upstream but is still located downstream of the 4.5-mil dot, whereas the apex of the second wedge is clearly located at the location of the 2-mil dot. Incipient transition from several of the other trip dots is apparent at various locations along the span. At $\mathrm{Re}_{\mathrm{ft}}=3.49 \mathrm{million} / \mathrm{ft}$ (figure 27) eight of the nineteen trip dots have caused the formation of turbulent wedges. Three of the trip dots located near the test article tip have forced transition in the region that, at lower Reynolds numbers, was primarily dominated by crossflow from the tip radius.

Figures 28-30 show transition patterns from flight 456 with the 2-D forward-facing steps. A yellow line showing the transition line for the clean test article from flight 452 at similar Reynolds numbers (figures 22-24) has been added to the figures for comparison. On this flight, the upper step had a height of 0.0135 inches and consisted of three layers of film. The lower step had a height of 0.0045 inches and consisted of a single layer of film. Figure 28 shows the transition pattern at the beginning of the descent at $\mathrm{Re}_{\mathrm{ft}}=2.23 \mathrm{million} / \mathrm{ft}(0.68 \mathrm{million} / \mathrm{m})$. The leading edges of both steps show up as a dark vertical line just downstream of the leading edge. The trailing edge of the upper step shows up as white vertical line located several inches behind the camera-pod shock. The trailing edge of the bottom step has the same longitudinal location as that of the upper step, but is not visible in the figure. A large turbulent wedge originating from the test article leading edge exists on the upper step. A post-flight inspection of the test article revealed a nick on the leading edge at this location. Runway debris kicked up from the airplane nose gear is thought to have caused the nick. A second turbulent wedge on the upper step is located at approximately 28 percent chord. This wedge is a direct effect of the disturbance caused by the step height. At approximately mid-span, a large turbulent wedge has formed from the bottom right corner of the forward face of the upper step. Even though both steps were tapered toward the trailing edge to account for turbulent wedge formation from the corners of the leading edge of each step, the bottom half of this turbulent wedge has encroached onto the upper portion of the lower step test area. A small section of the flow over the lower step remains laminar past the aft portion of the step and beyond the camera-pod shock. An incipient wedge can be seen approximately midway down the lower step, but the majority of the flow over the lower step is laminar. Two small turbulent wedges are apparent near 
the test article tip upstream of the step. The source of these wedges is not known at this time. Figure 29 shows the transition pattern for $\mathrm{Re}_{\mathrm{ft}}=2.68 \mathrm{million} / \mathrm{ft}(0.817 \mathrm{million} / \mathrm{m})$. A small turbulent wedge from the top corner of the bottom step has formed. With the exception of the two wedges near the tip leading edge, the transition line on the lower step is not significantly different from that of the clean test article (yellow line). At $\mathrm{Re}_{\mathrm{ft}}=3.49$ million/ft (figure 30) the transition line on both steps has moved appreciably forward. Two small areas of incipient transition have formed on the lower portion of the upper step. The transition pattern on the lower step closely resembles that of the clean test article.

\section{Summary}

A flight test series was undertaken to investigate the extent of supersonic laminar flow on a specially designed natural laminar flow test article using the NASA F-15B research test bed airplane. The test article was designed with no leading edge sweep to eliminate spanwise pressure gradients that result in boundary layer crossflow. An onboard digital infrared imaging system was used to characterize the transition front, and thus, the extent of laminar flow on the test article. The infrared images clearly show the boundary layer transition line and other flow features such as shock waves impinging on the test article. Results from the flights showed laminar flow in excess of 80 percent chord for portions of the span at chord Reynolds number in excess of 14 million. At higher Reynolds numbers, transition was dominated by crossflow induced by a series of parallel shocks located over approximately the front third of the test article. The presence of these shocks was undesirable, as they created a spanwise pressure gradient and an adverse chordwise pressure gradient, both of which are destabilizing to boundary layer transition mechanisms. A number of flights were flown with discrete and 2-D roughness elements installed on the test article. The results from the disturbance flights will be used to benchmark allowable roughness tolerances intrinsic to the construction and operation of a supersonic business jet class airplane.

\section{Nomenclature:}

$\begin{array}{ll}\text { CF } & \text { crossflow (transition mechanism) } \\ \text { CLIP } & \text { Centerline Instrumented Pylon } \\ \mathrm{Hp} & \text { pressure altitude } \\ \text { IR } & \text { infrared } \\ \text { LE } & \text { leading edge } \\ \text { M } & \text { Mach number } \\ \text { Minf } & \text { free-stream Mach number } \\ \text { M }_{\infty} & \text { free-stream Mach number } \\ \text { NASA } & \text { National Aeronautics and Space Administration } \\ \text { NLF } & \text { natural laminar flow } \\ \text { r } & \text { recovery factor (0.88 for turbulent boundary layer) } \\ \text { Re } & \text { Reynolds number } \\ \text { Re } & \text { unit Reynolds number } \\ \text { RTD } & \text { Resistance Temperature Detector } \\ \text { SBJ } & \text { Supersonic Business Jet } \\ \text { SBLT } & \text { Supersonic Boundary Layer Transition (project) } \\ \text { SSNLF } & \text { Supersonic Natural Laminar Flow (project) } \\ T_{\text {Tot }} & \text { free-stream total temperature } \\ T_{\text {turb }} & \text { turbulent adiabatic wall temperature }\end{array}$


$\mathrm{T}_{\infty}$

free-stream static temperature

$\alpha$

angle of attack (airplane reference frame)

$\beta$

flank angle of attack (airplane reference frame)

ratio of specific heats ( 1.4 for air)

\section{References}

1. Kroo I. Unconventional configurations for efficient supersonic flight. VKI Lecture Series on Innovative Configurations and Advances Concepts for Future Civil Aircraft, June 2005.

2. Saric W. 3-D boundary-layer stability and transition, AIAA 2010 Short Course: Stability and Transition: Course Notes, Chicago, Illinois, Ch. 4, pp. 1-29, 2010.

3. Reed H. and Saric W. Transition mechanisms for transport aircraft. $38^{\text {th }}$ Fluid Dynamics Conference and Exhibit, Seattle, Washington, AIAA 2008-3743, 2008.

4. Mack L. Boundary-layer linear stability theory. Special Course on Stability and Transition of Laminar Flow, AGARD Report, No. 709, pp. 3-1 - 3-81, 1984.

5. Arnal D. Three-dimensional boundary layers: laminar-turbulent transition. Computation of Three-Dimensional Boundary Layers Including Separation, AGARD Report, No. 741, pp. 4-1 - 4-34, 1986.

6. Reshotko E. Boundary layer instability, transition, and control. $32^{\text {nd }}$ Aerospace Sciences Meeting \& Exhibit, Reno, Nevada, AIAA 94-0001, 1994.

7. Sturdza P. An aerodynamic design method for supersonic natural laminar flow aircraft. PhD. Thesis, Stanford University, Palo Alto, California, USA, 2003.

8. United States Patent No. 5,322,242, June 21, 1994, Richard R. Tracy, Carson City, Nevada.

9. Sturdza P. Extensive supersonic natural laminar flow on the Aerion business jet. $45^{\text {th }}$ AIAA Aerospace Sciences Meeting and Exhibit, Reno, Nevada, AIAA 2007-685, 2007.

10. Garzon G. and Matisheck J. Supersonic testing of natural laminar flow on sharp leading edge airfoils. Recent experiments by Aerion corporation. $42^{\text {nd }}$ AIAA Fluid Dynamics Conference and Exhibit, New Orleans, Louisiana, AIAA 2012-3258, 2012.

11. Banks D, van Dam C, Shiu H and Miller G. Visualization of in-flight flow phenomena using infrared thermography. NASA TM/2000-209027, 2000.

12. Van Dam C, Shiu H, Banks D, Tracy R and Chase J. In-flight visualization of supersonic flow transition using infrared imaging. Journal of Aircraft, Vol. 39, No. 6, pp. 936-944, November-December 2002.

13. Banks D, Frederick M, Tracy R, Matisheck J and Vanacek N. In-flight boundary-layer transition on a large flat plate at supersonic speeds. 15 $5^{\text {th }}$ International Symposium on Flow Visualization, Minsk, Belarus, 2012.

14. Schlichting H. Boundary-Layer Theory. Seventh edition, McGraw-Hill Book Company, 1979. 


\section{Figures}

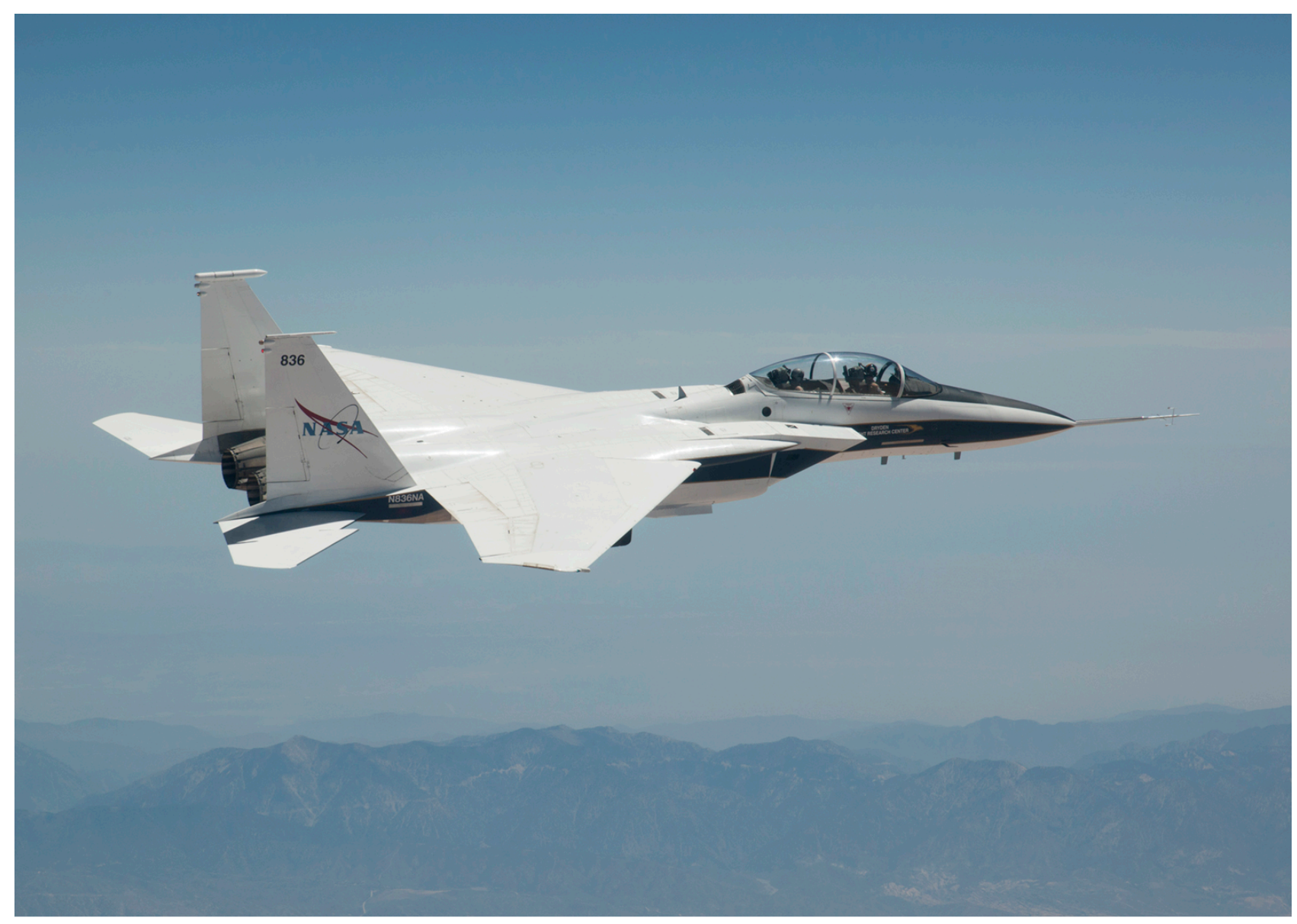

Fig. 1. The NASA F-15B research test bed airplane. 


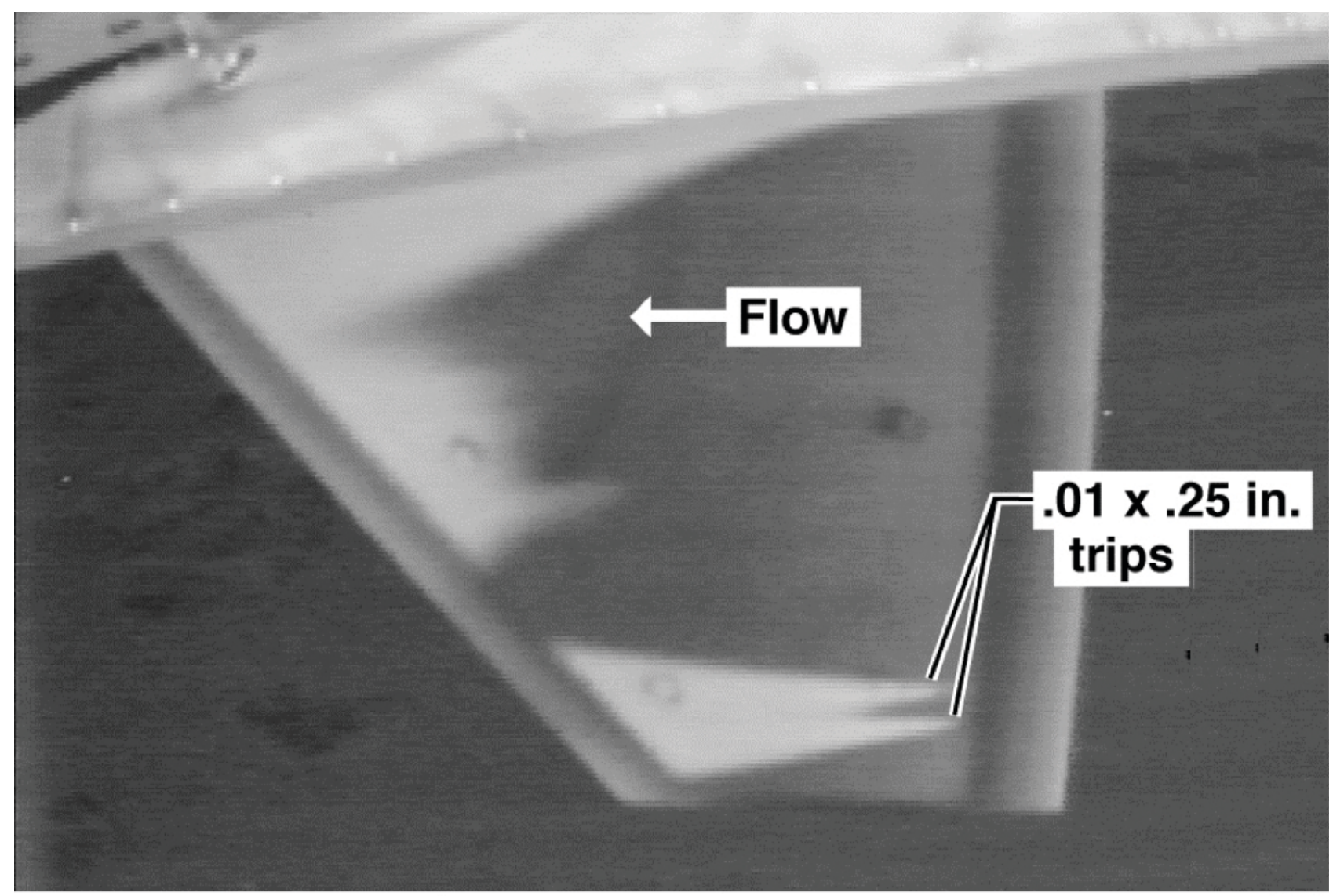

Fig. 2. Infrared measurements from the SSNLF test article on the NASA F-15B research test bed airplane.

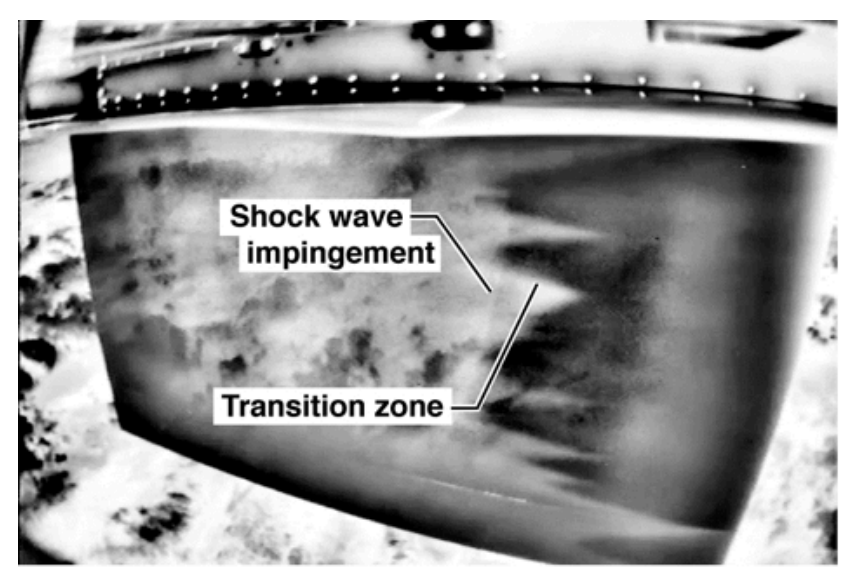

(a)

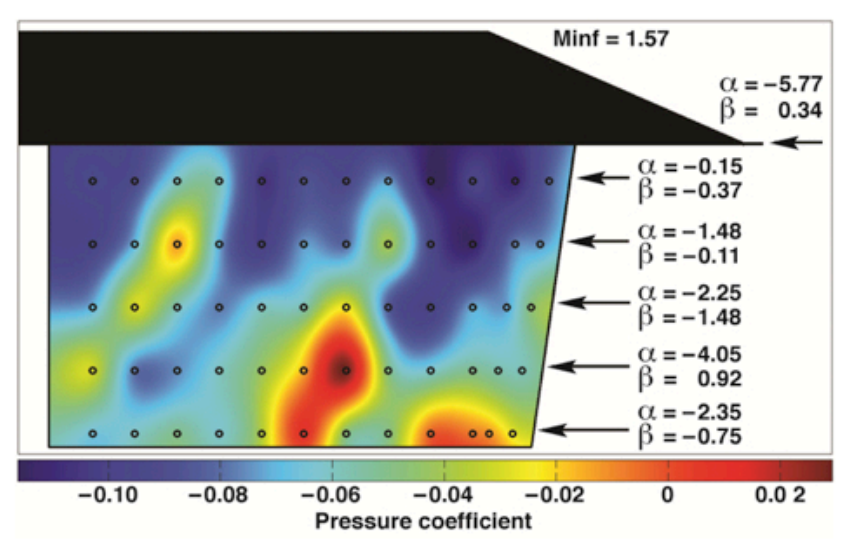

(b)

Fig. 3. Infrared (a) and (b) local flow measurements from the SBLT phase 1 flat-plate test article on the NASA F-15B research test bed airplane. 


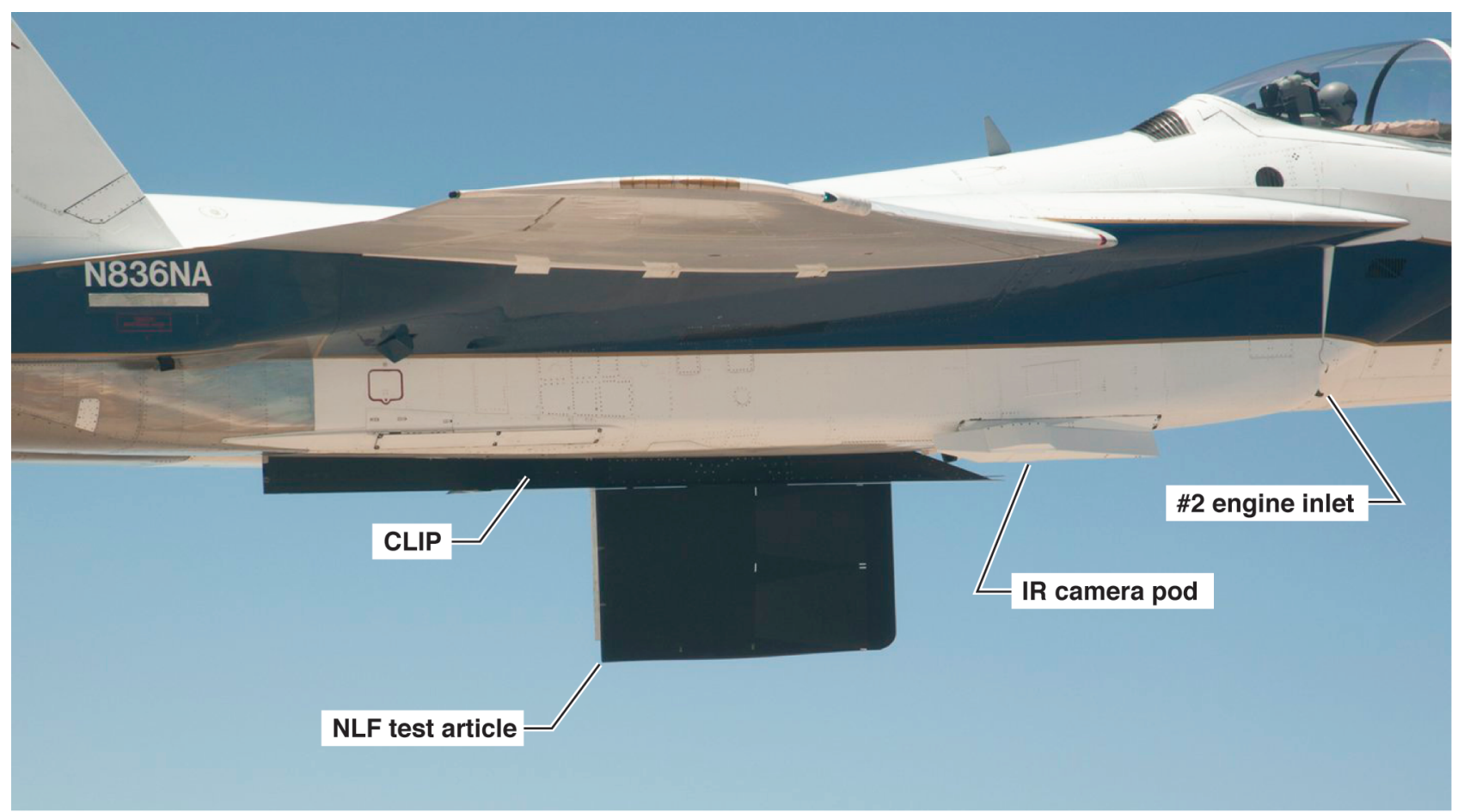

Fig. 4. The IR camera pod and NLF test article on the NASA F-15B research test bed airplane.

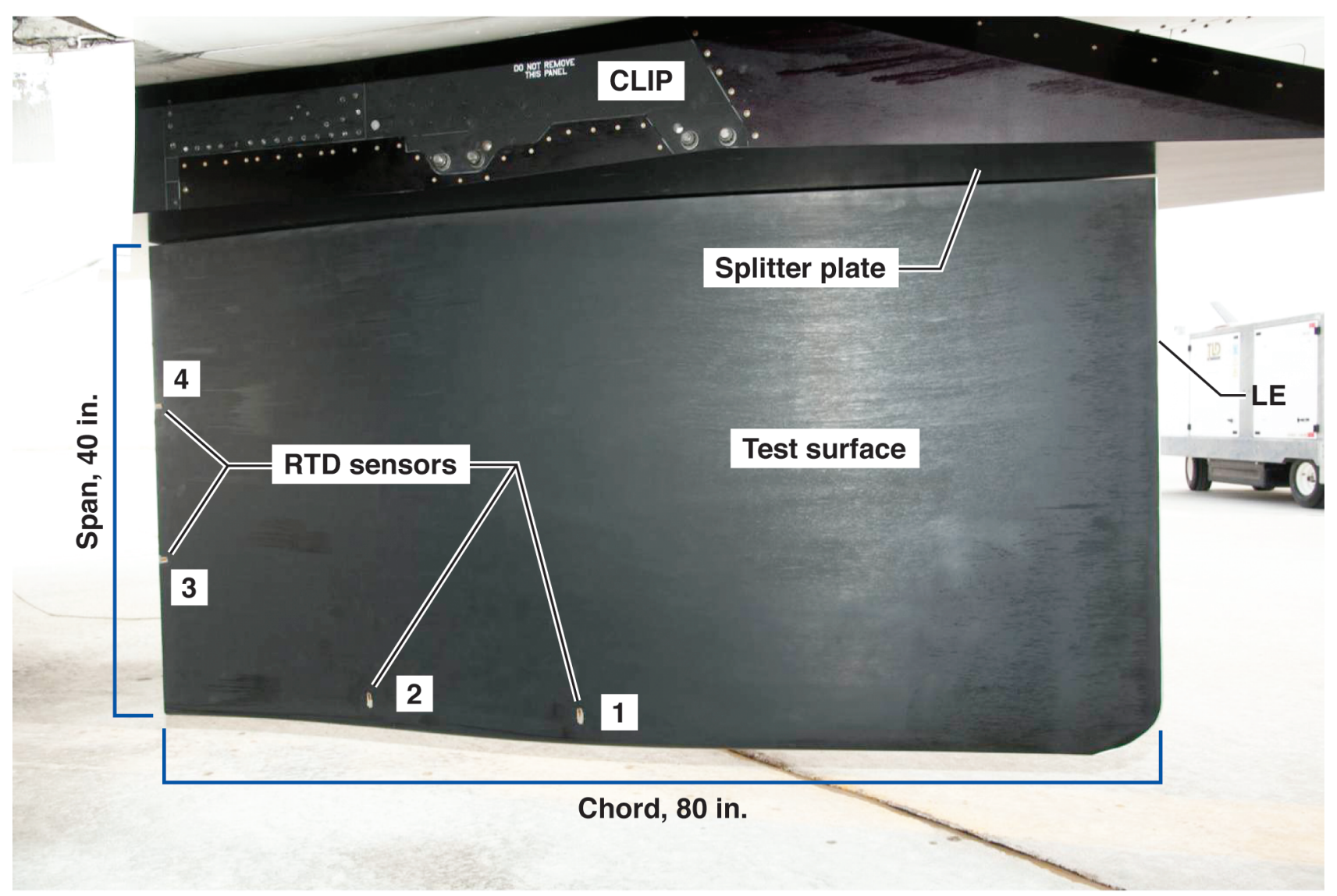

Fig 5. The SBLT phase 2 NLF test article mounted underneath the NASA F-15B research test bed airplane. 


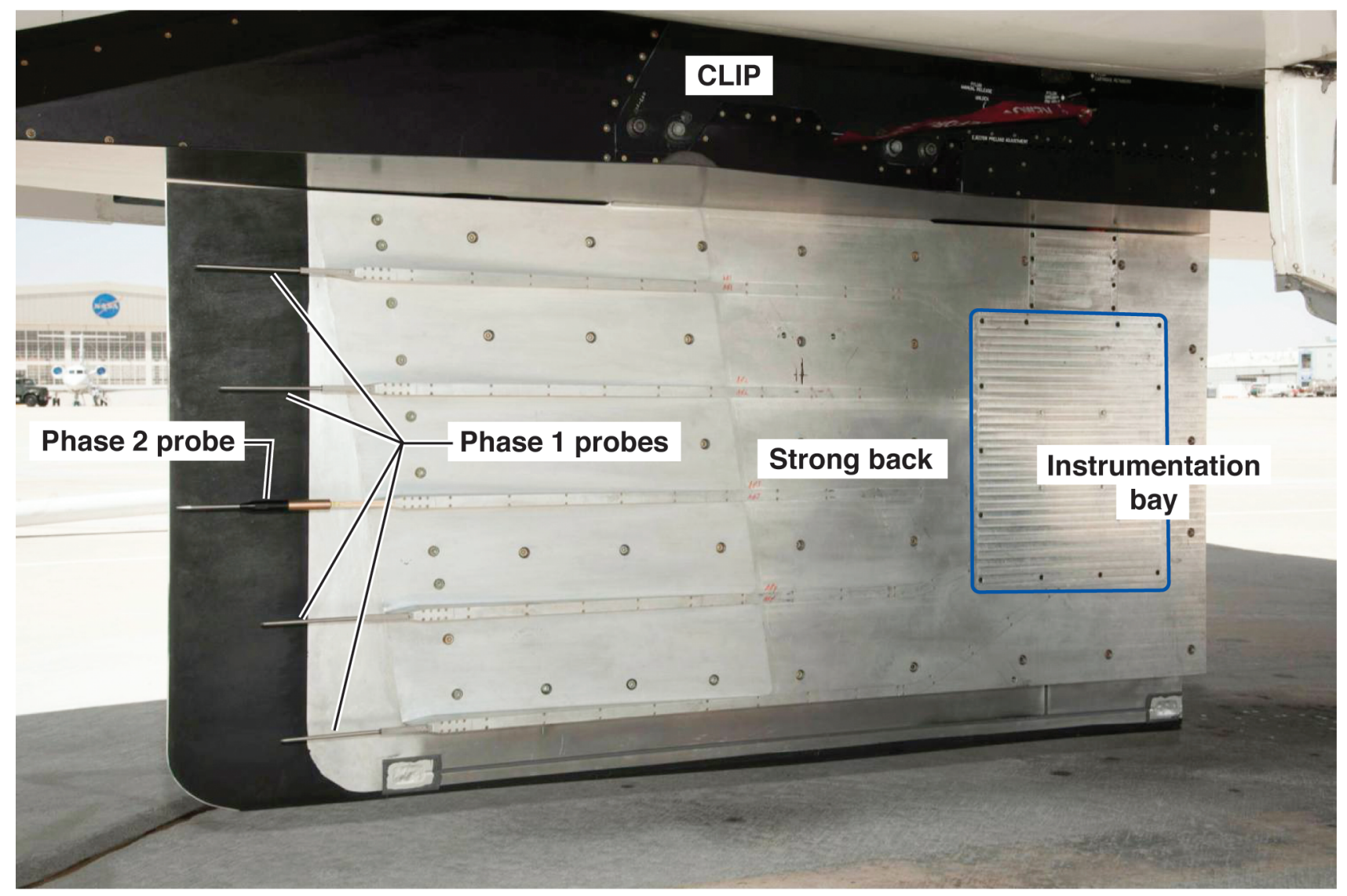

Fig. 6. The back side of the phase 2 NLF test article showing the strong back, conical probes, and instrumentation bay.

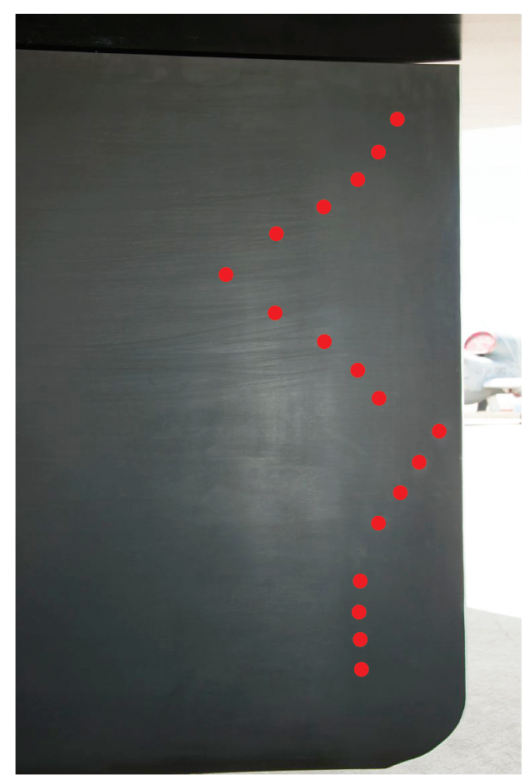

(a)

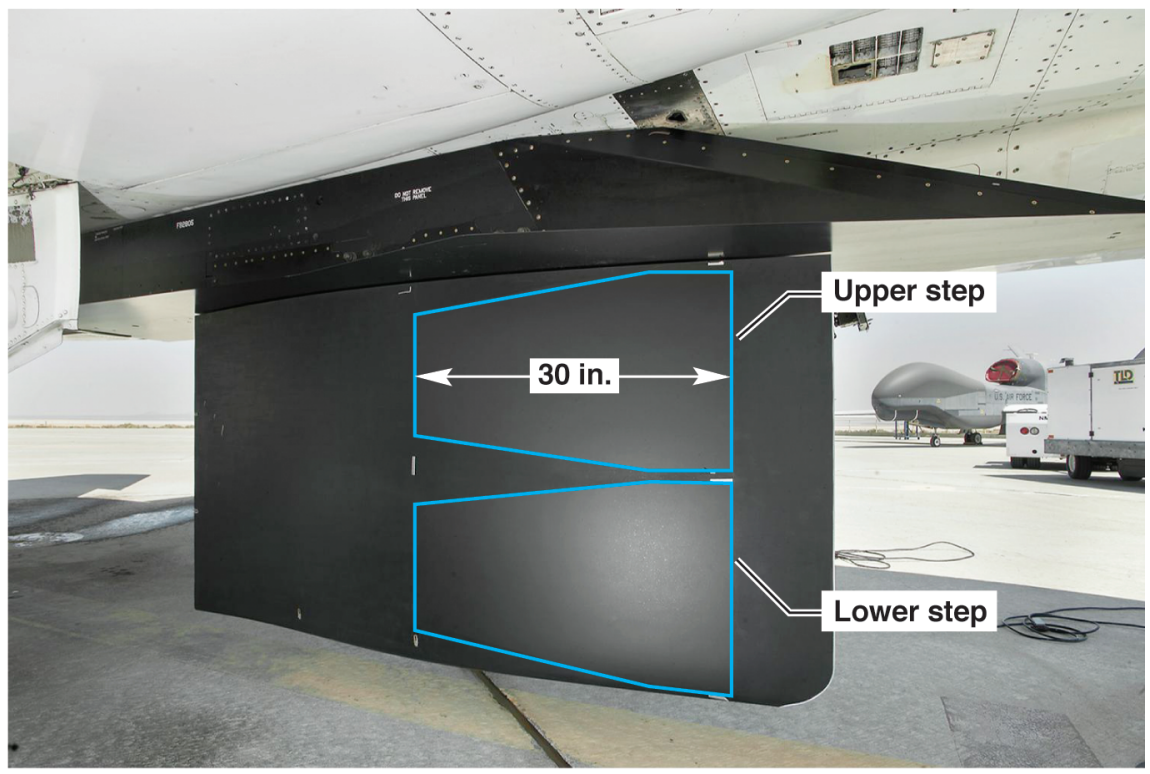

(b)

Fig. 7. (a) Discrete roughness elements near the leading edge highlighted in red; and (b) 2-D steps outlined in blue. 


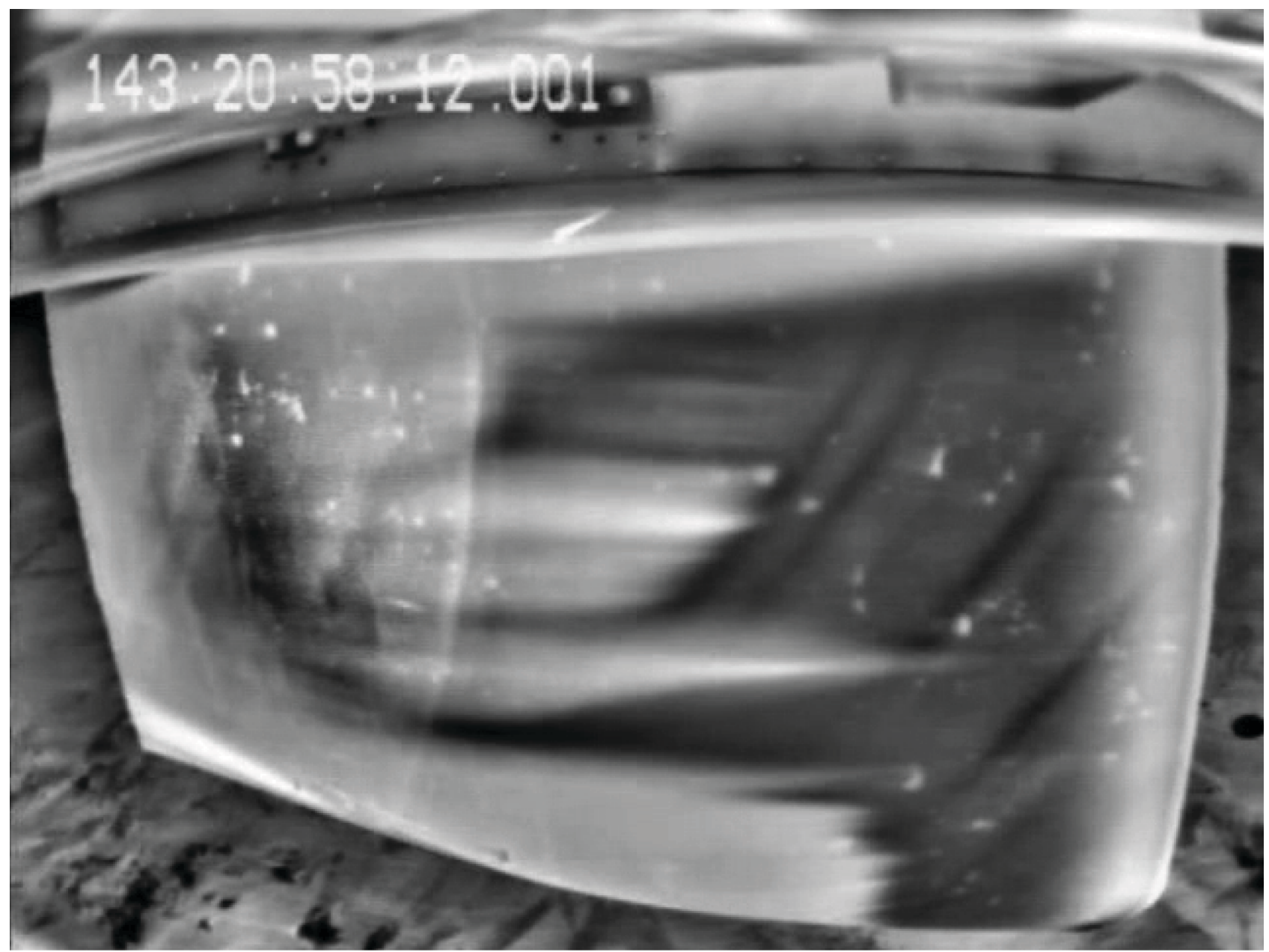

Fig. 8. Analog IR image from the SBLT phase 2 flight showing image distortion.

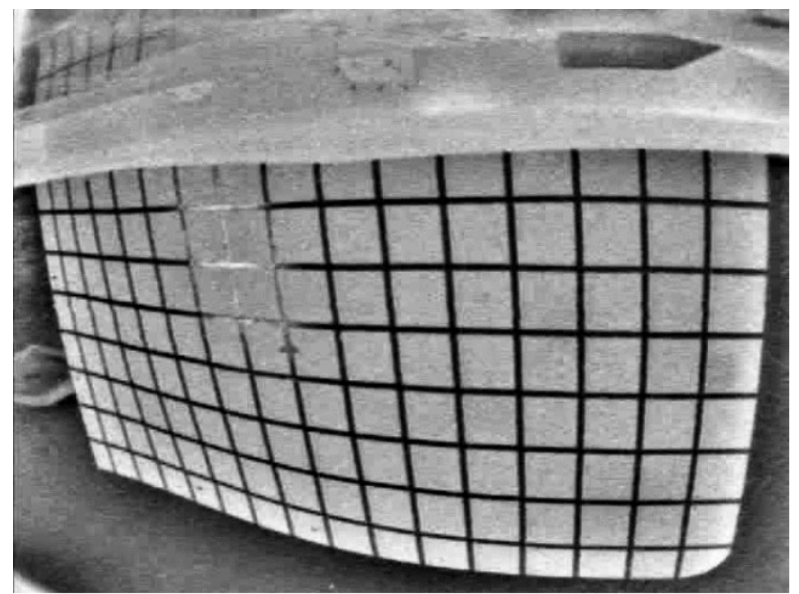

(a)

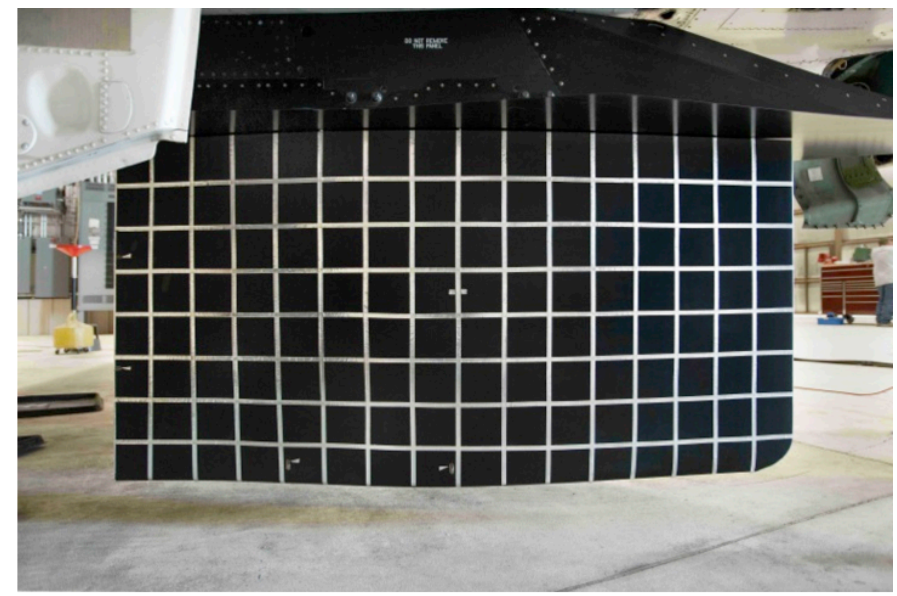

(b)

Fig. 9. (a) Analog IR image; and (b) photo of the calibration grid used for IR image transformation. 


\section{Flight $=452 \quad$ Mach $=1.714 \quad-\mathrm{Hp}=43898 \quad \mathrm{Re}_{\mathrm{ft}}=2.805 \mathrm{e}+06$}

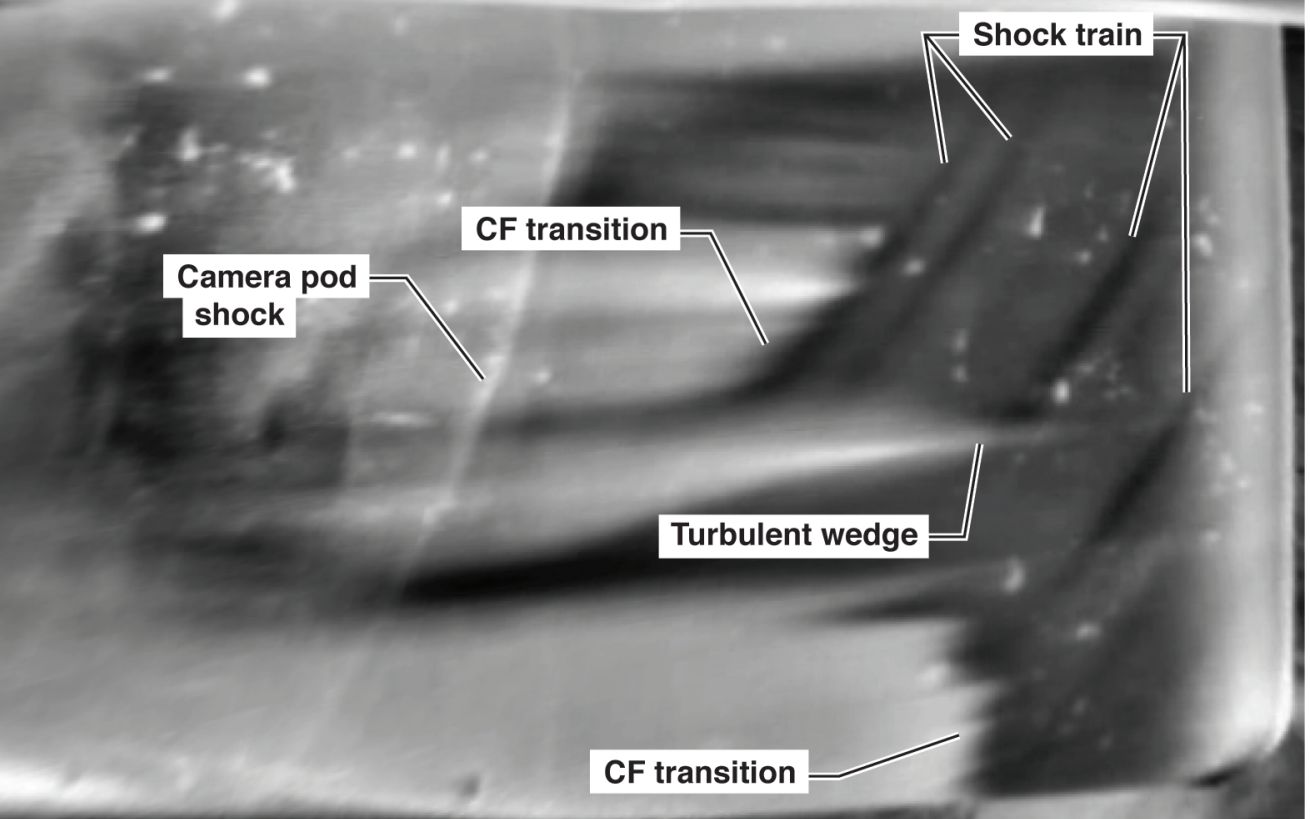

Fig. 10. Transformed analog IR image showing important flow phenomena. 


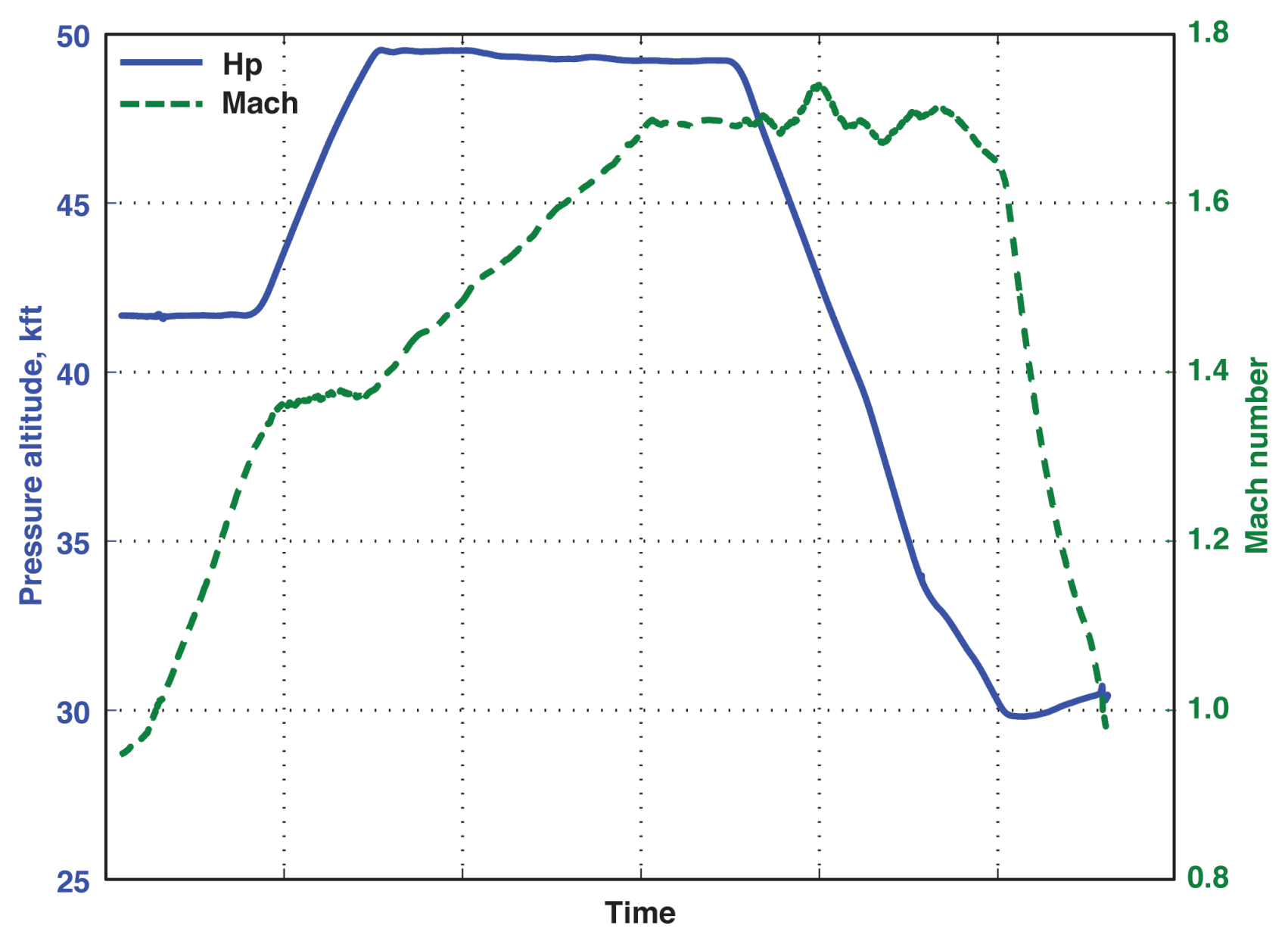

Fig. 11. Flight 452, profile 2 with Mach 1.7 descent to $33,000 \mathrm{ft}$. 


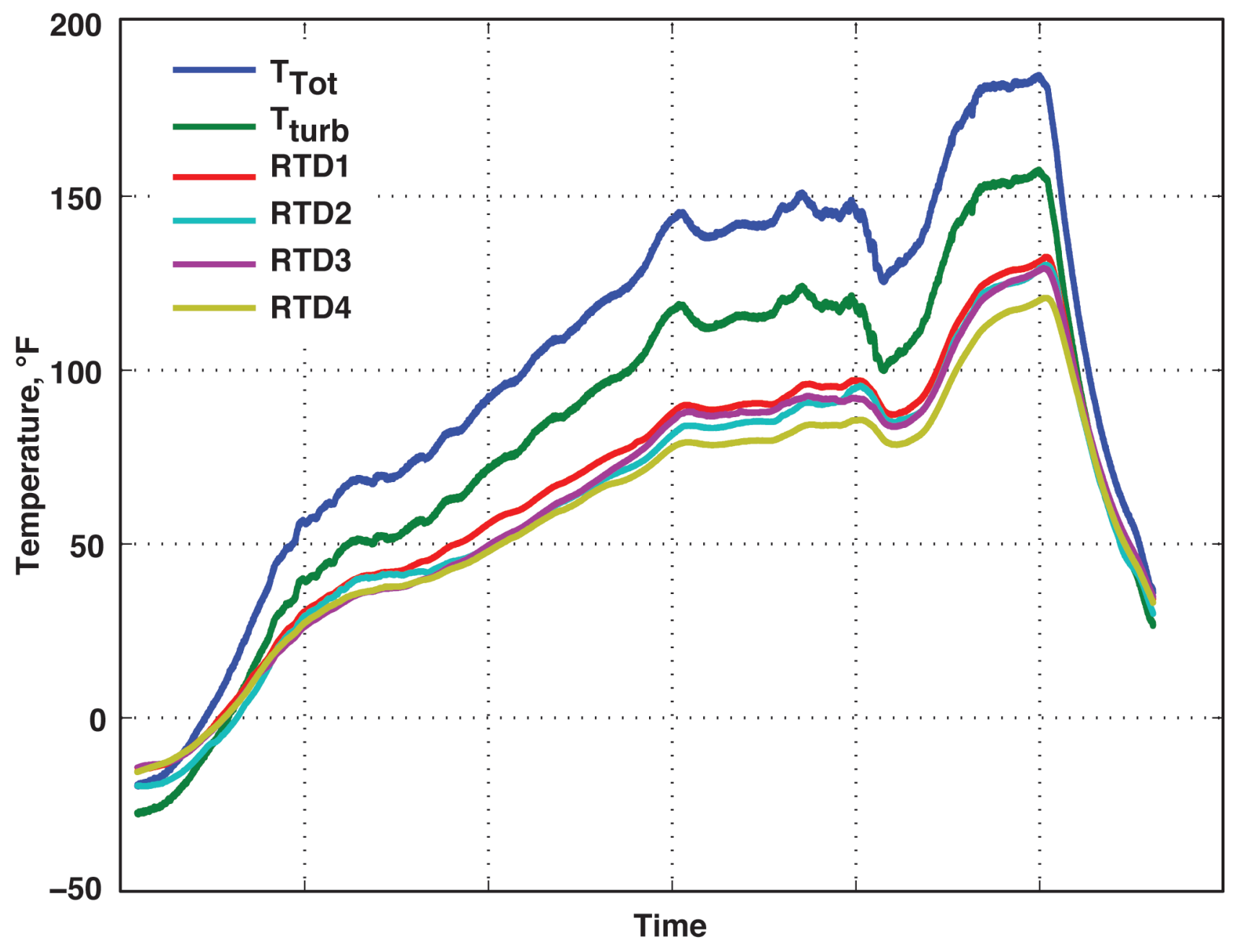

Fig. 12. Flight 452, free-stream and test article surface temperatures. 


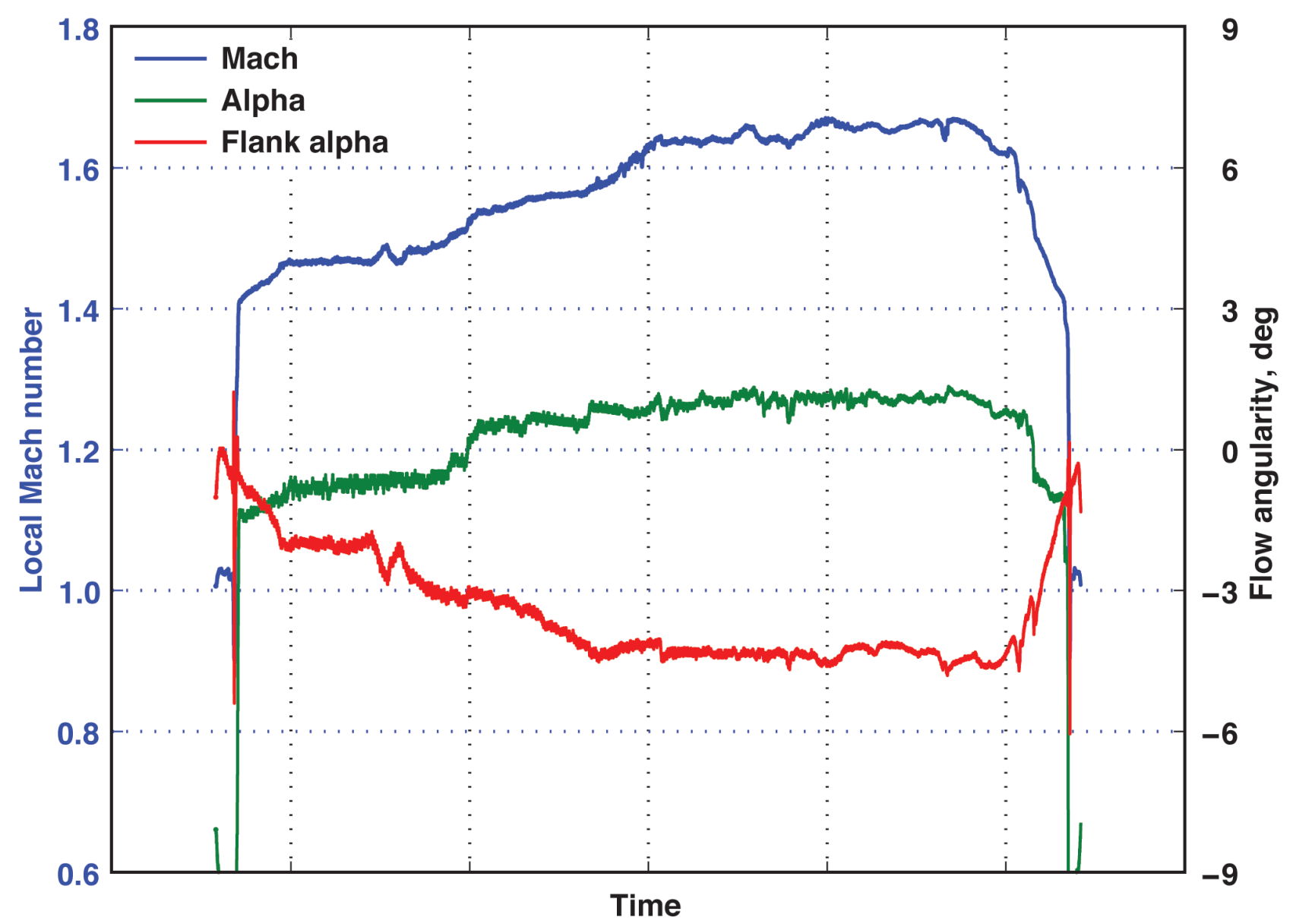

Fig. 13. Flight 452, test article flow conditions at the mid-span measured from the phase 2 probe. 
FLIGHT TESTS OF A SUPERSONIC NATURAL LAMINAR FLOW AIRFOIL

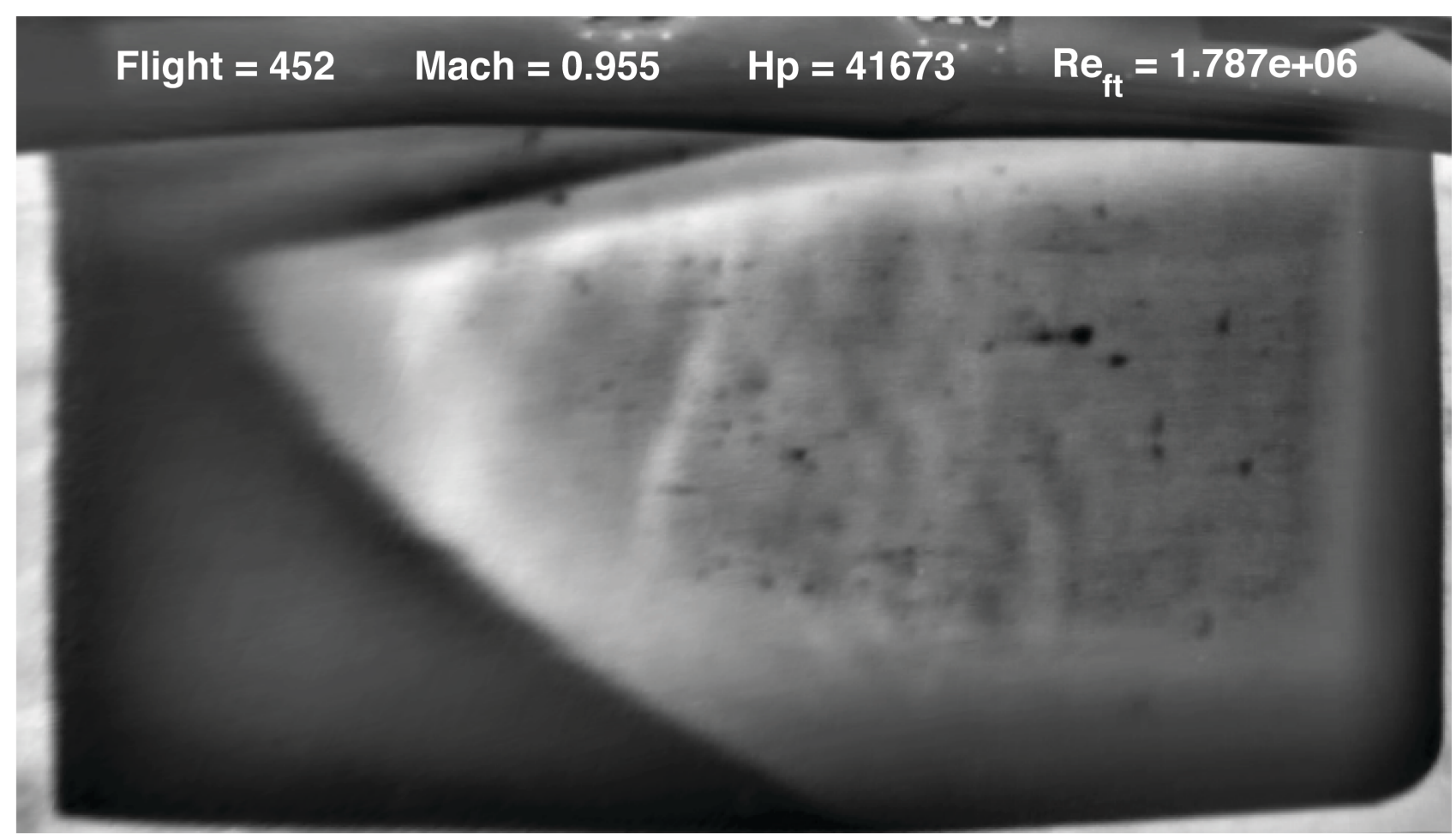

Fig. 14. Mach $=0.95$ during initial acceleration at 42,000 ft.

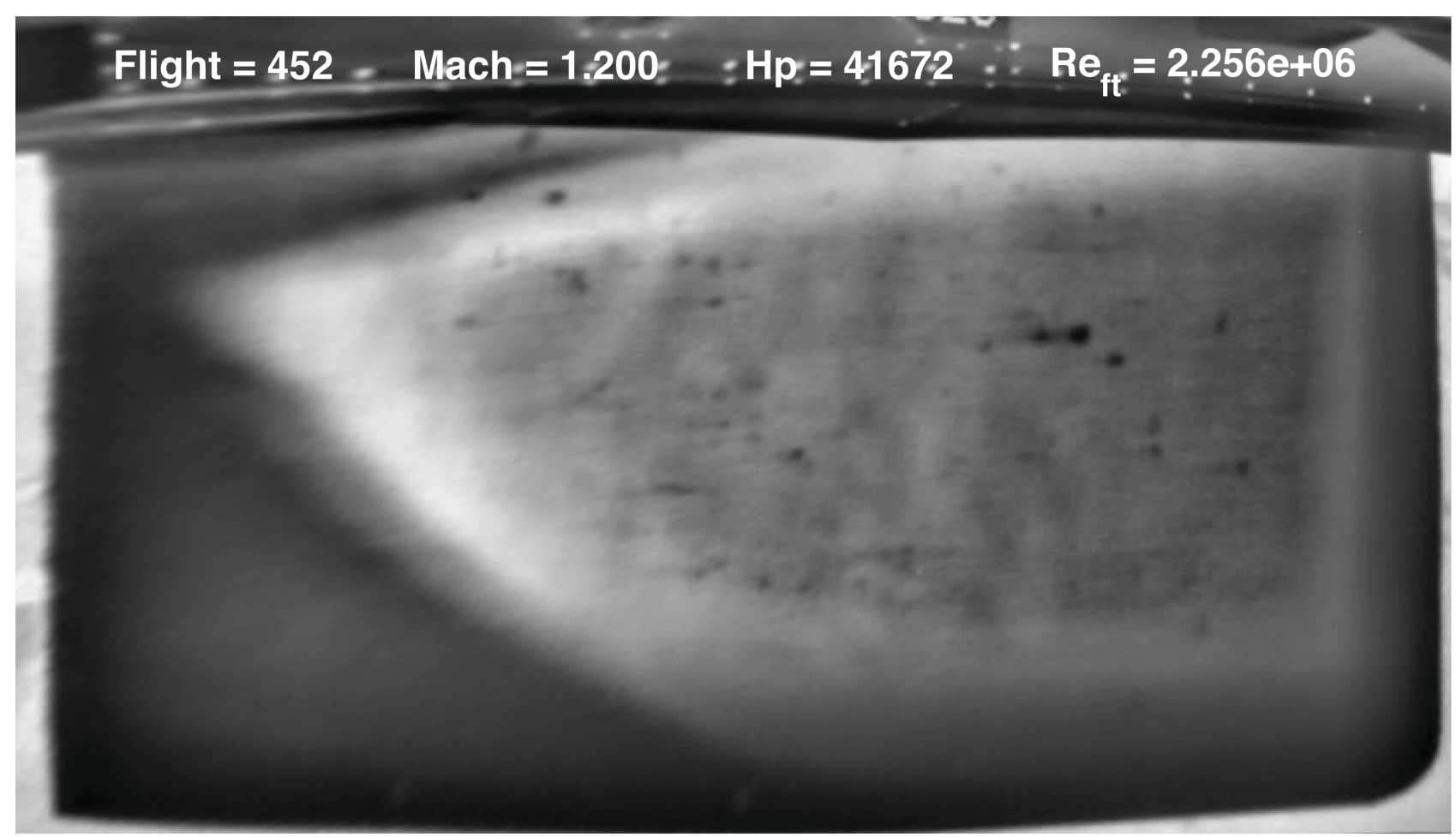

Fig. 15 . Mach $=1.2$ during initial acceleration at 42,000 ft. 


\section{Flight $=452-$ Mach $=1: 300 \quad: H p=41714 \therefore R e_{i t}=2.421 \mathrm{e}+06$}

Fig. 16. Mach $=1.3$ during initial acceleration at 42,000 ft.

\section{Flight $=452-$ Mach $=1,350 \quad: H p=42707 \quad \therefore \mathrm{Re}_{\mathrm{ff}}=2,397 \mathrm{e}+06$}

Fig. 17. Mach $=1.35$ during constant Mach climb to $49,500 \mathrm{ft}$. 


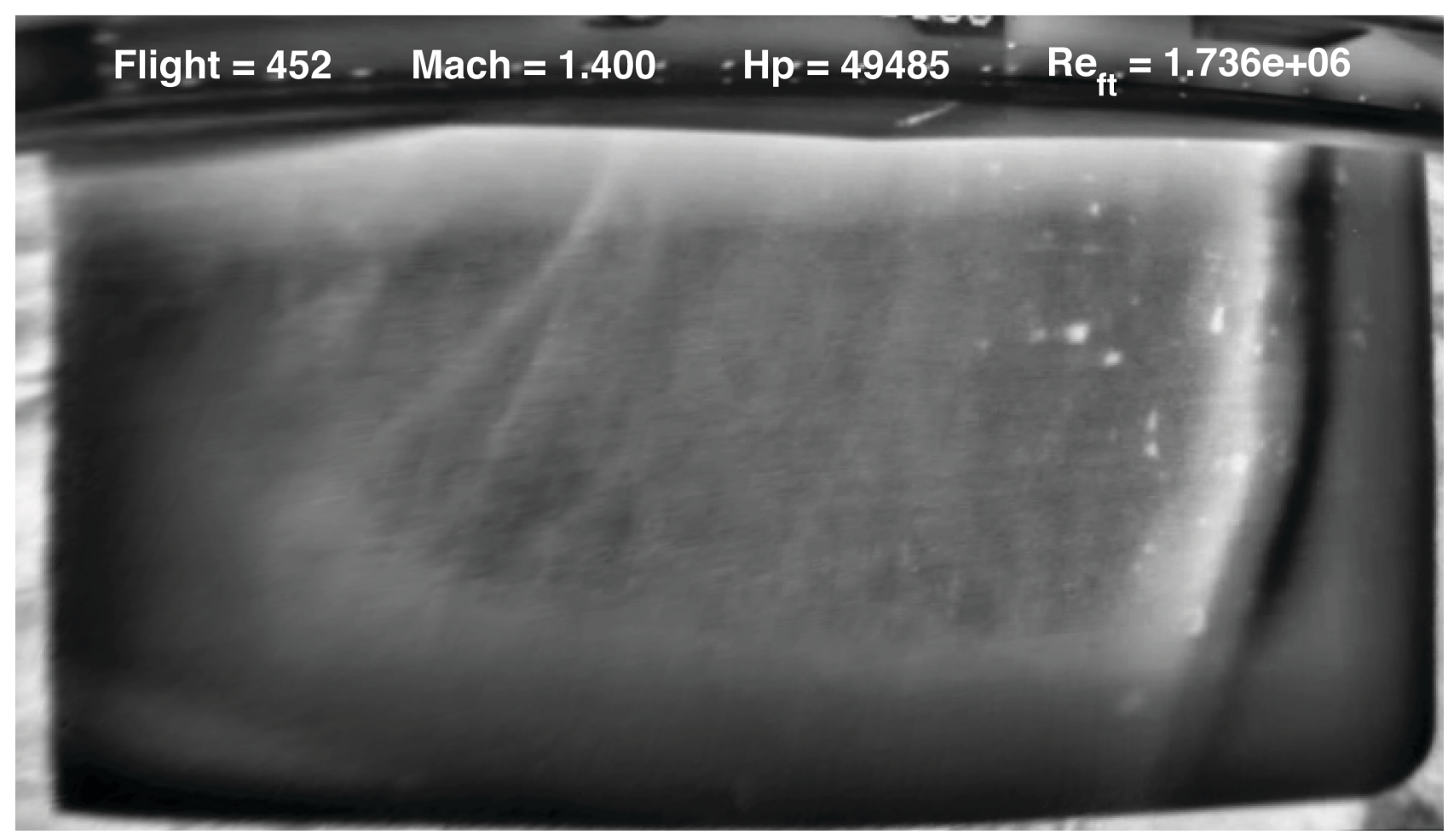

Fig. 18. Mach $=1.4$ during acceleration at $49,500 \mathrm{ft}$.

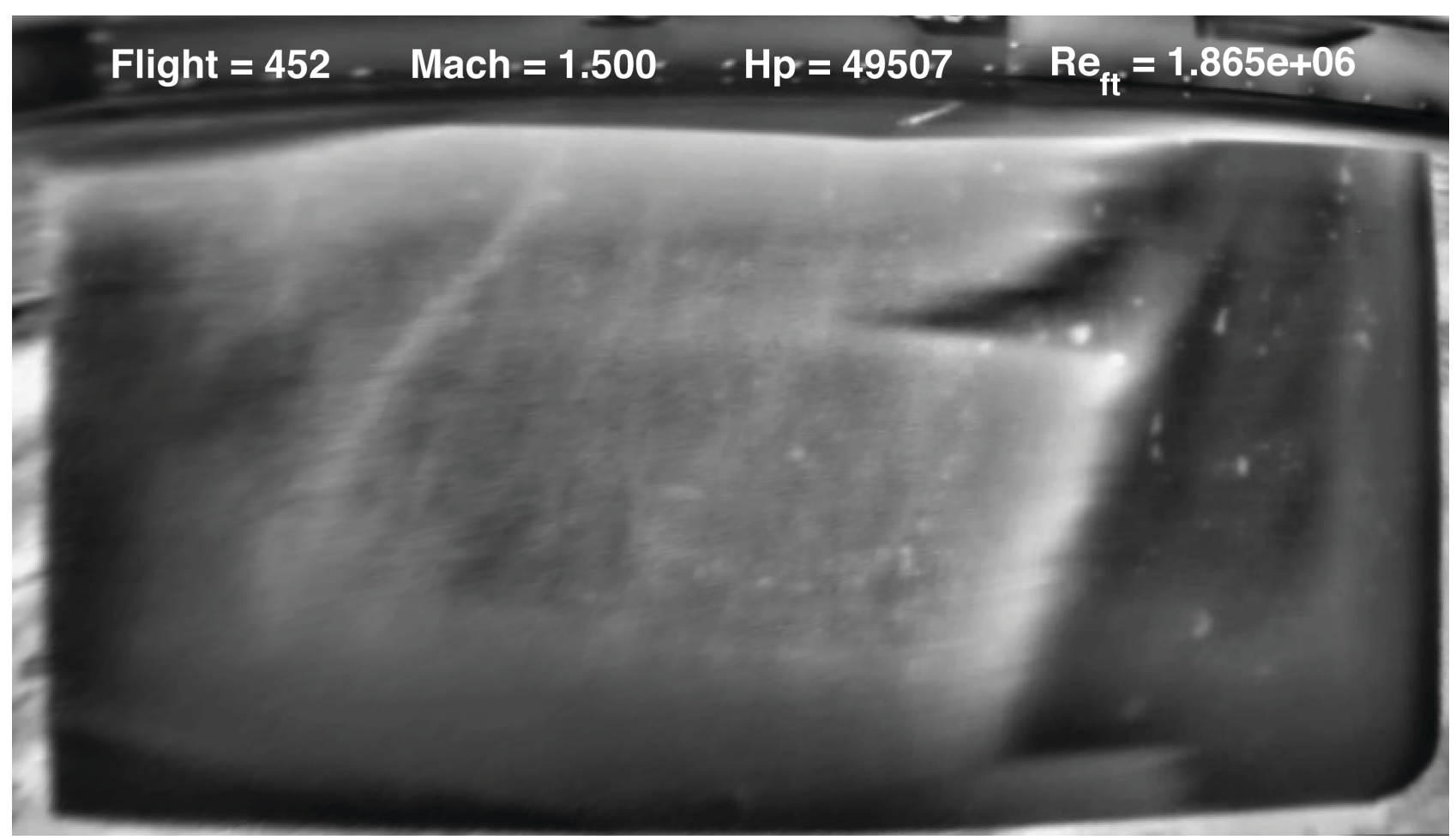

Fig. 19. Mach $=1.5$ during acceleration at $49,500 \mathrm{ft}$. 


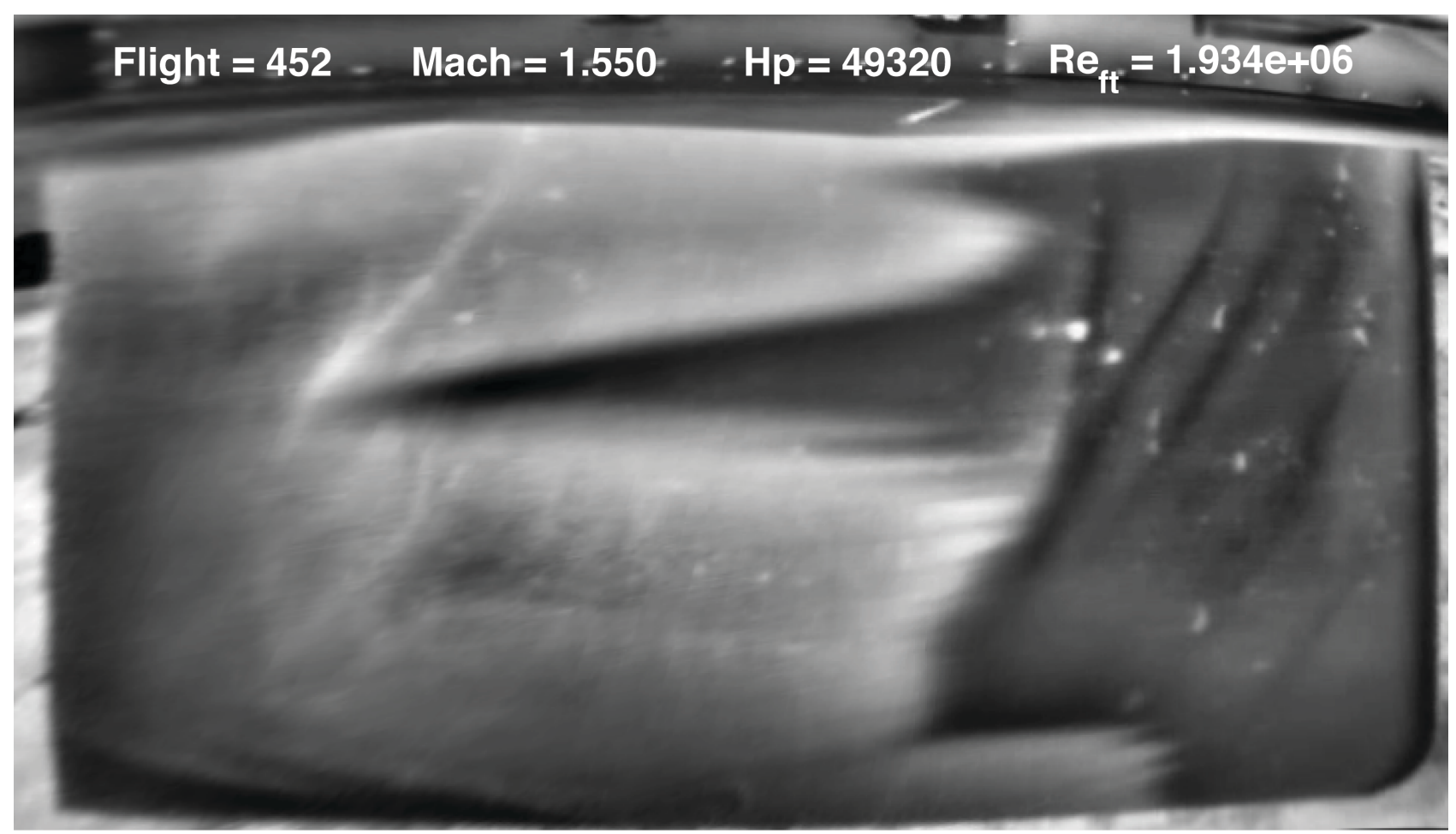

Fig. 20. Mach $=1.55$ during acceleration at 49,500 ft.

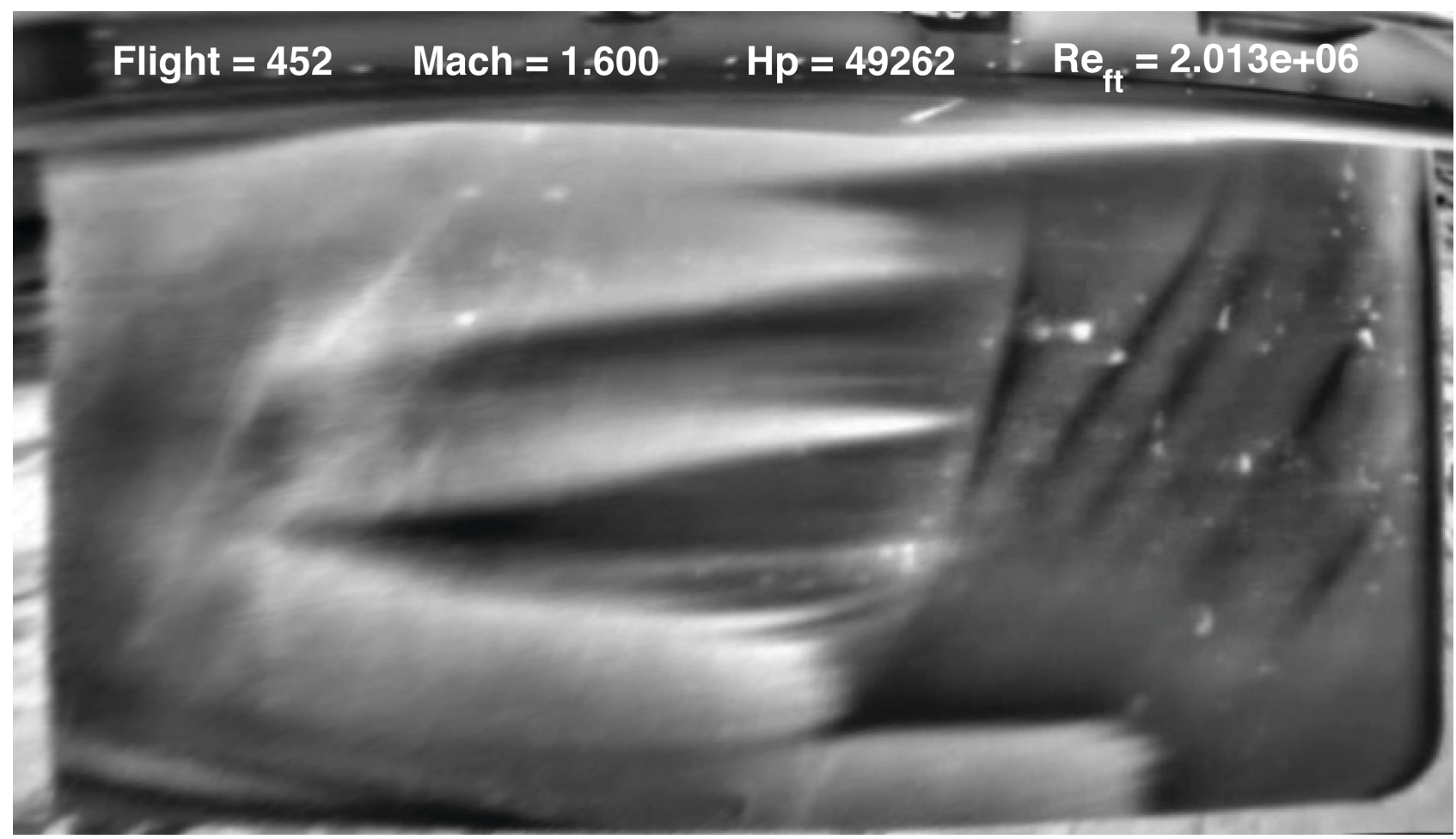

Fig. 21. Mach $=1.6$ during acceleration at 49,500 ft. 


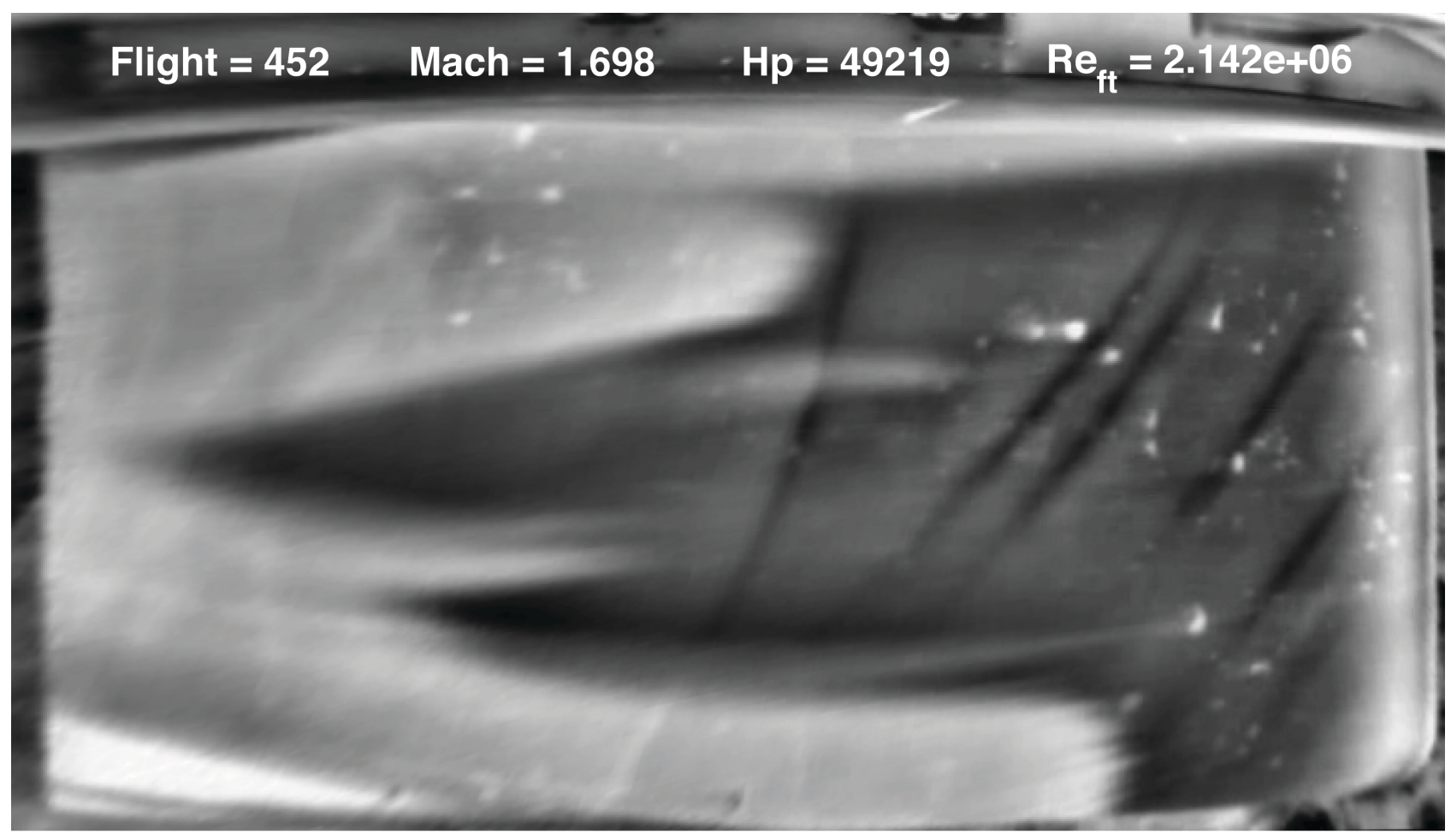

Fig. 22. Mach $=1.7$ at end of acceleration at 49,500 ft.

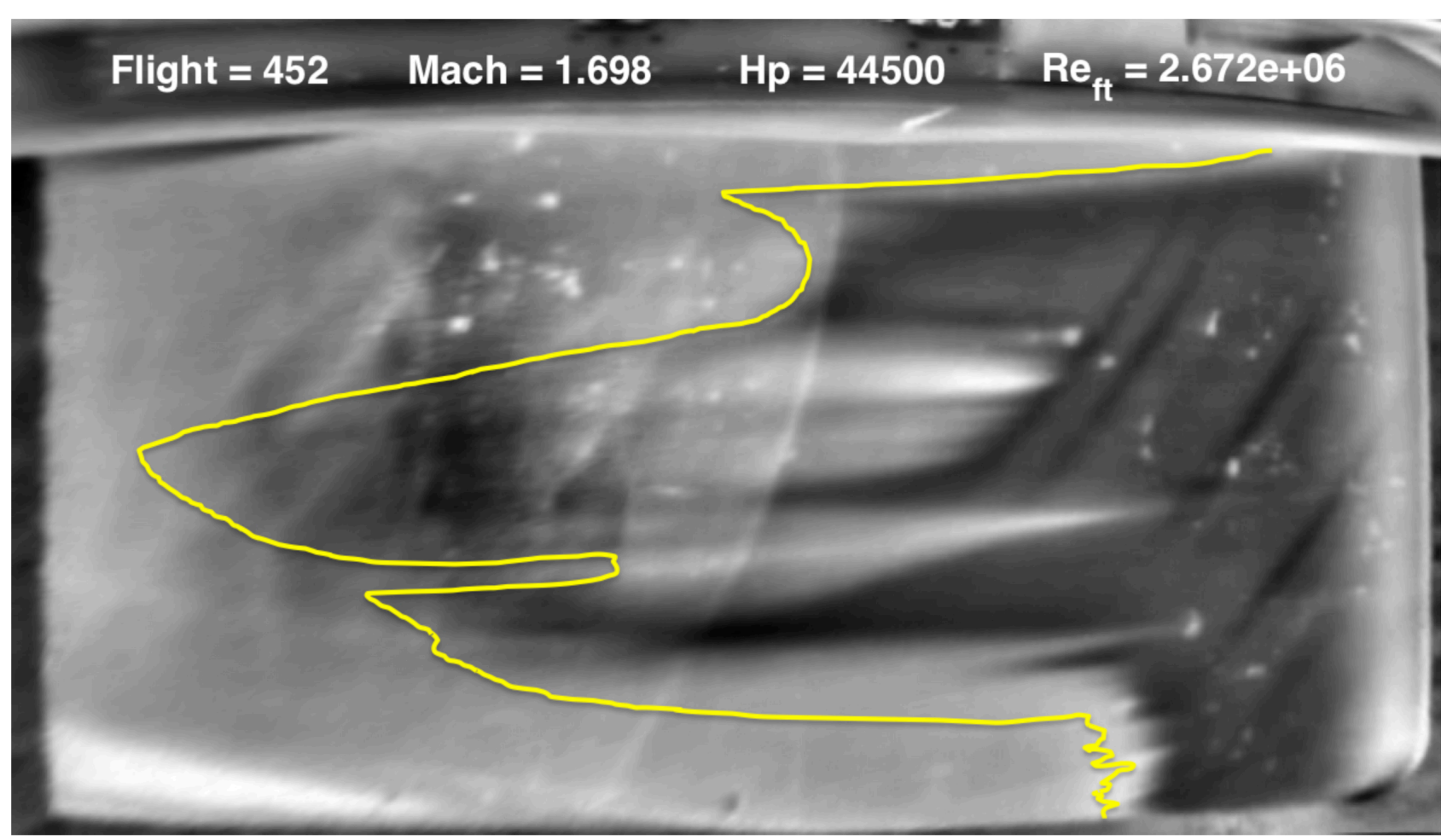

Fig. 23. Mach $=1.7, \mathrm{Re}_{\mathrm{ft}}=2.67 \mathrm{million} / \mathrm{ft}$. 


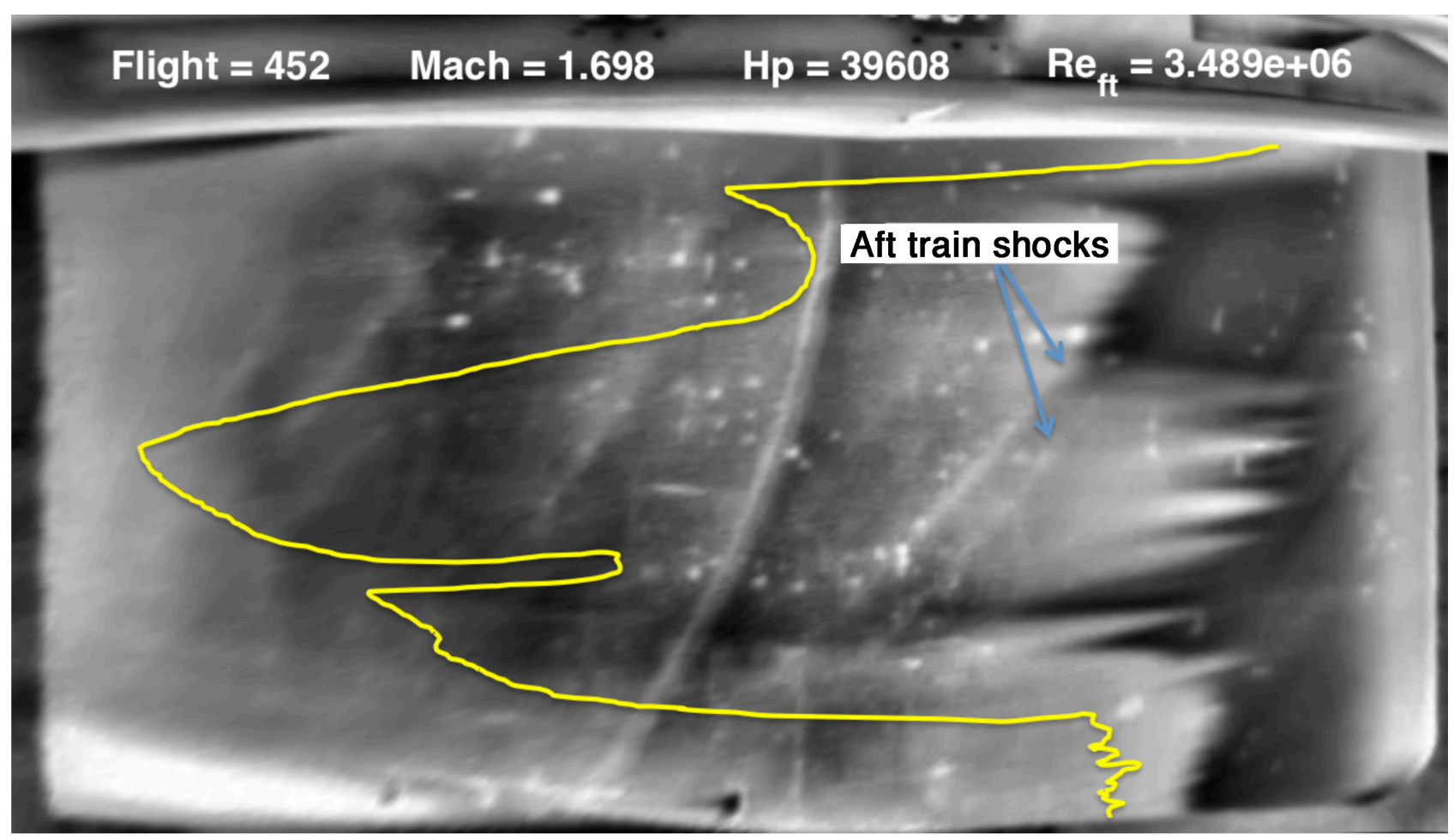

Fig. 24. Mach $=1.7, \mathrm{Re}_{\mathrm{ft}}=3.49 \mathrm{million} / \mathrm{ft}$.

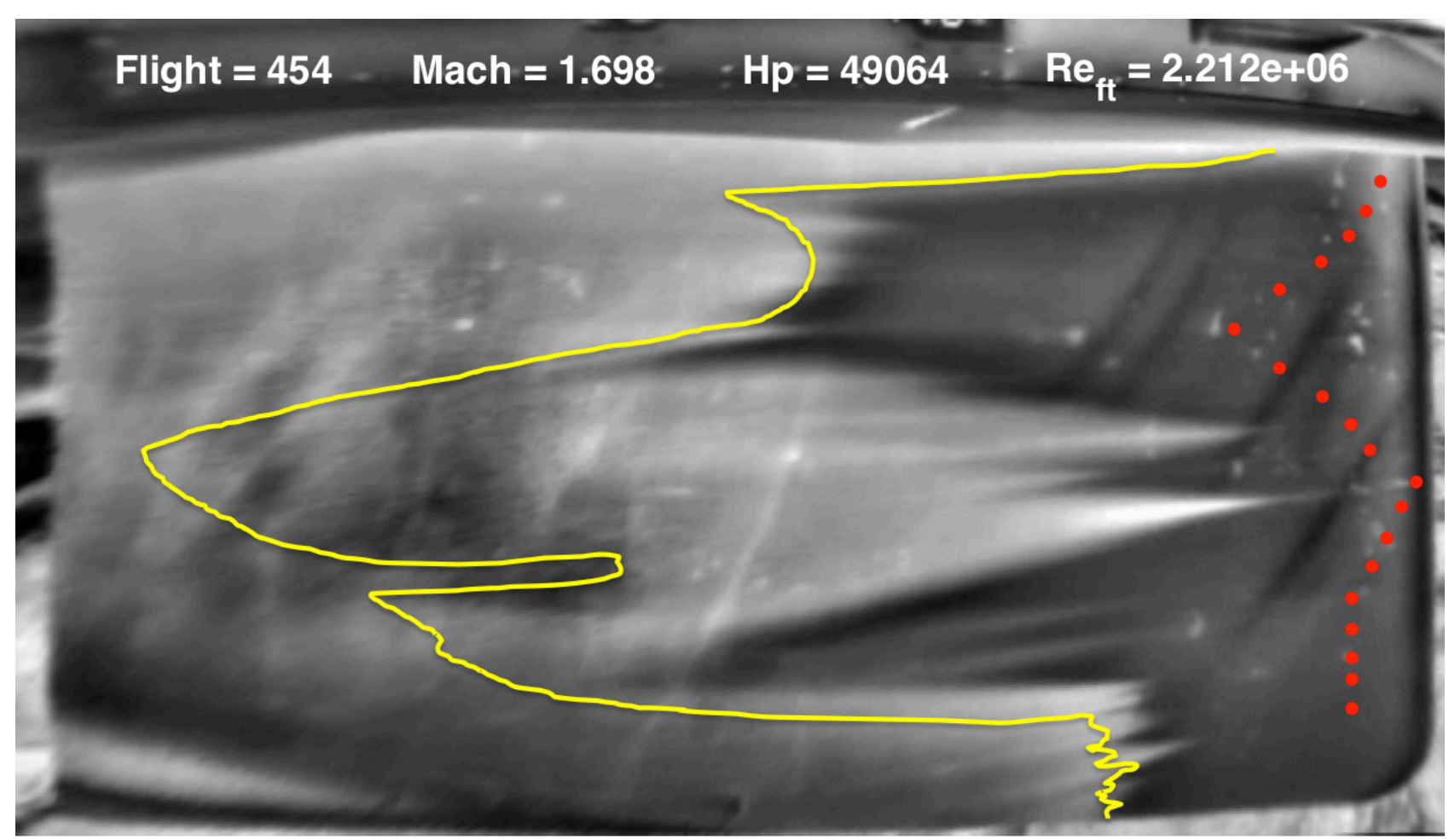

Fig. 25. Mach $=1.7, \mathrm{Re}_{\mathrm{ft}}=2.21 \mathrm{million} / \mathrm{ft}$ with trip dots (red highlight). 


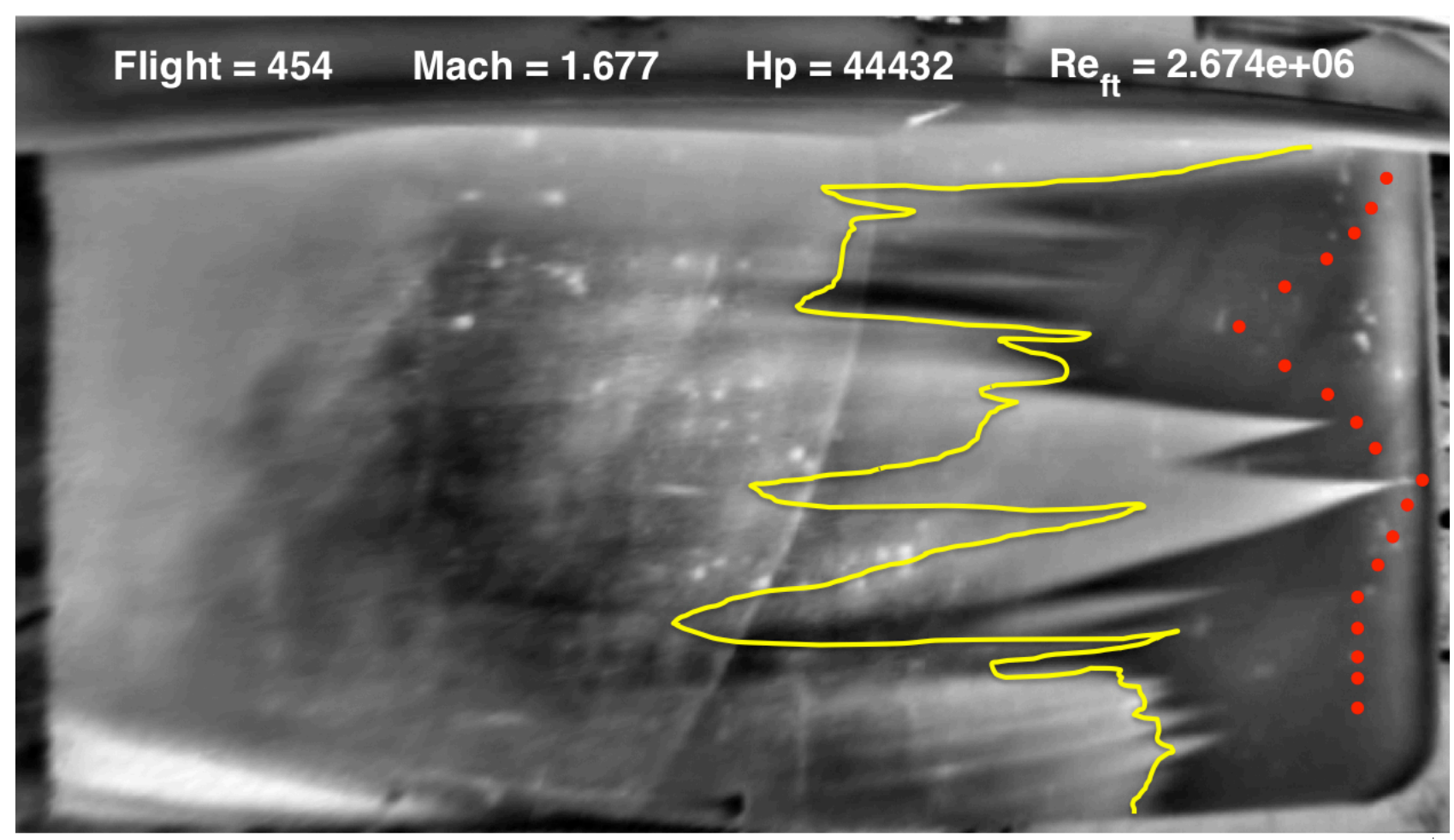

Fig. 26. Mach $=1.68, \mathrm{Re}_{\mathrm{ft}}=2.67$ million/ft with trip dots (red highlight)

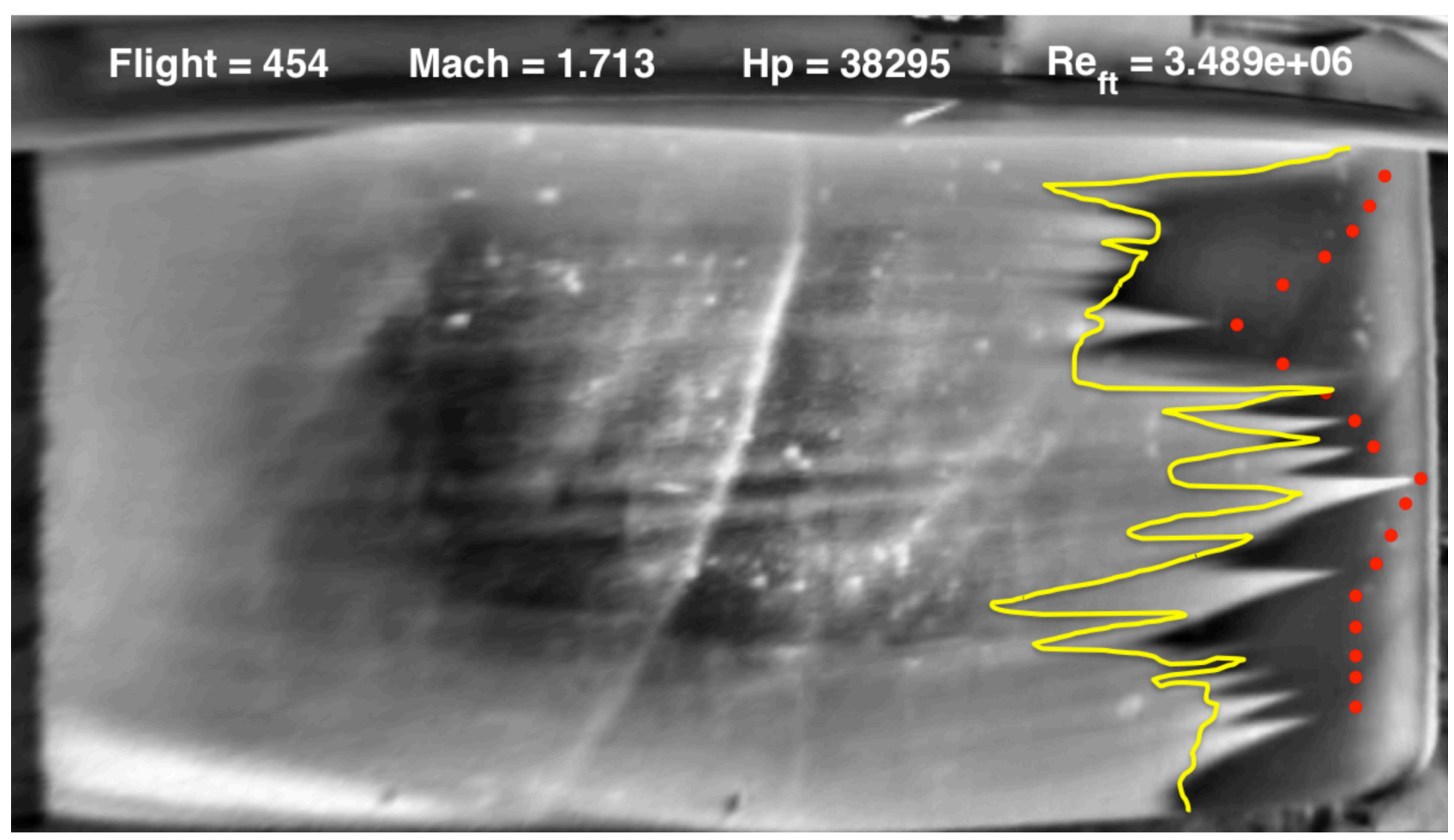

Fig. 27. Mach $=1.71, \mathrm{Re}_{\mathrm{ft}}=3.49$ million $/ \mathrm{ft}$ with trip dots (red highlight). 


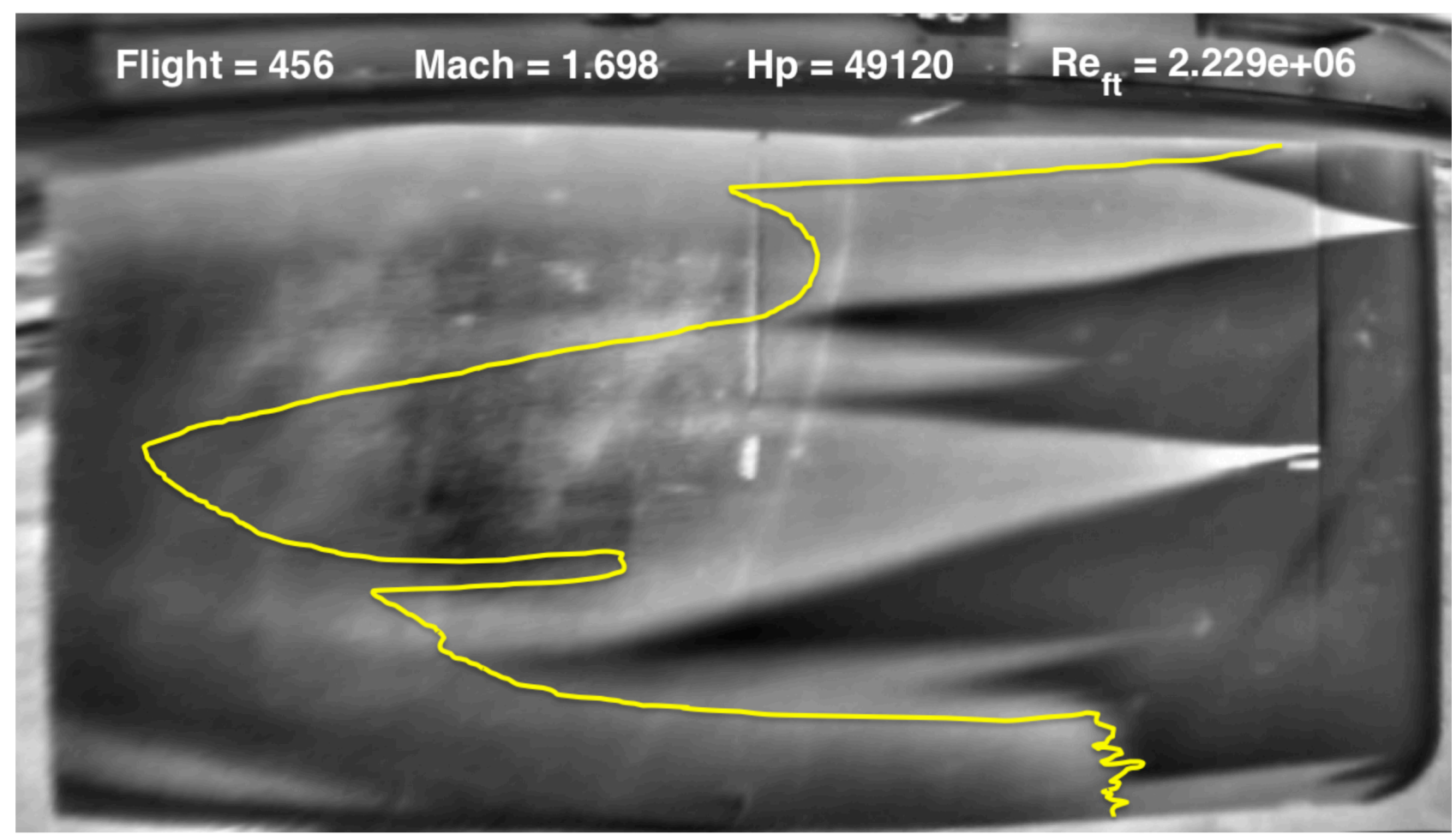

Fig. 28. Mach $=1.7, \mathrm{Re}_{\mathrm{ft}}=2.23$ million/ft with 2-D forward-facing steps.

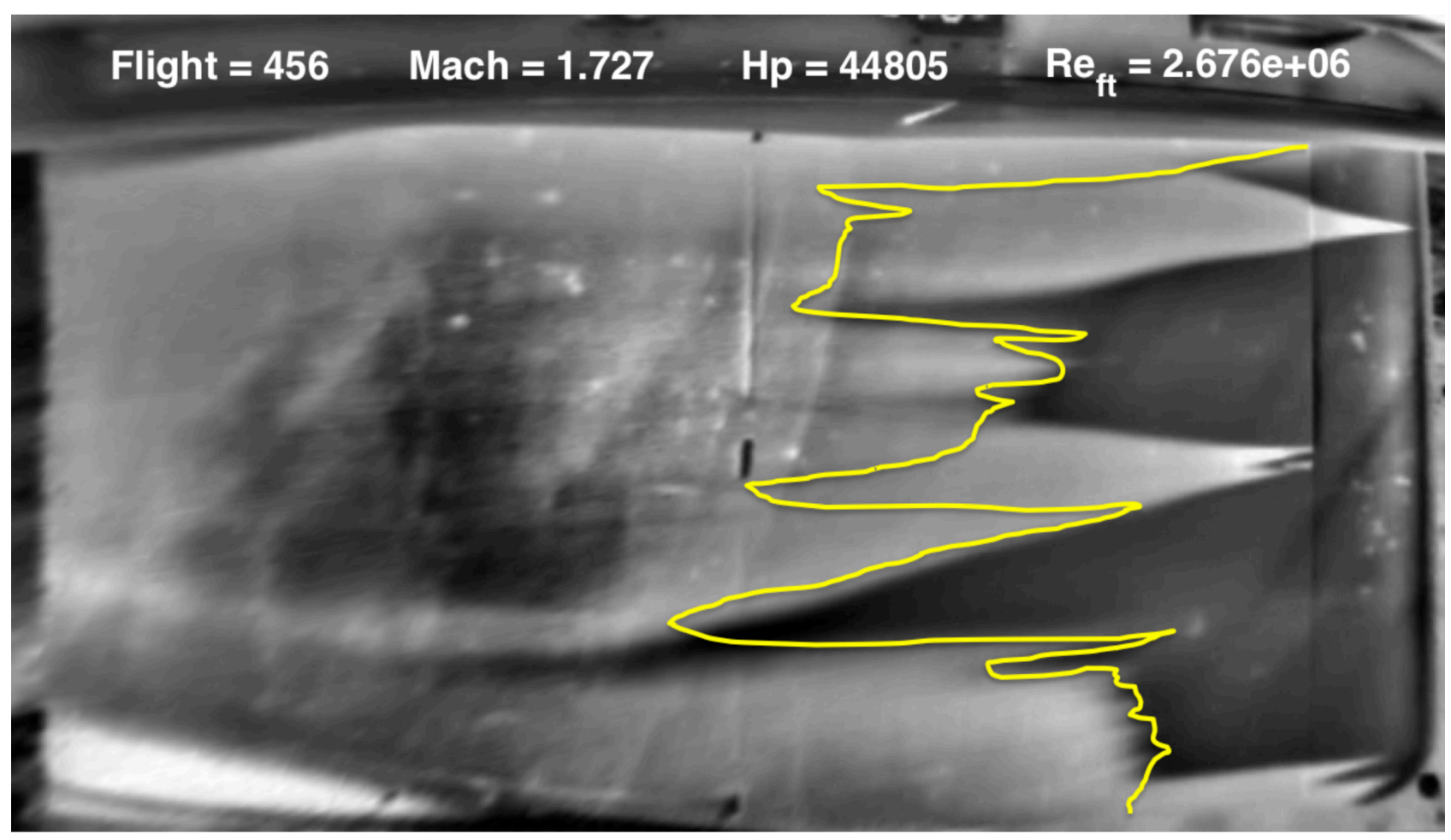

Fig. 29. Mach $=1.73, \mathrm{Re}_{\mathrm{ft}}=2.68$ million/ft with 2 -D forward-facing steps. 


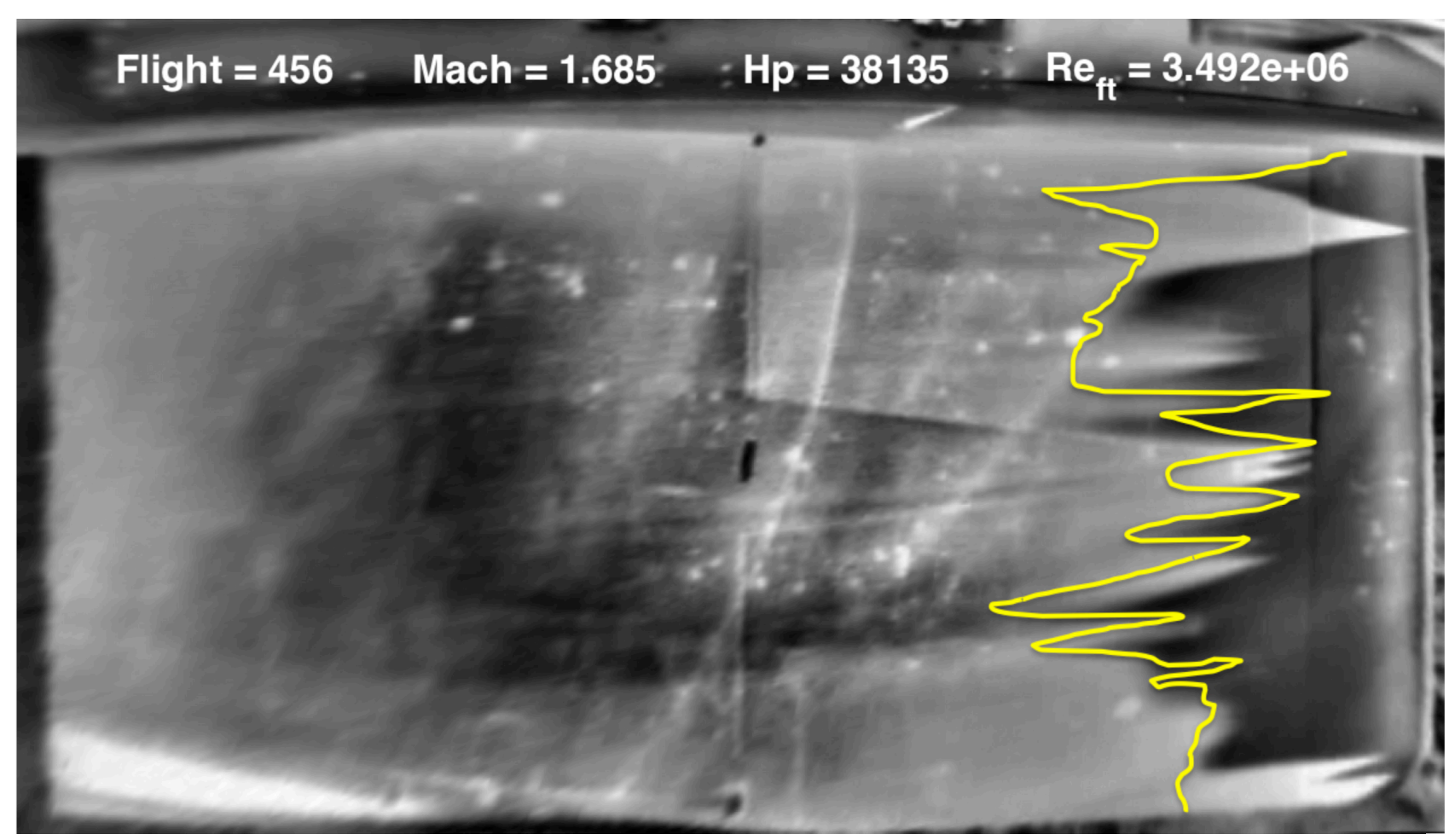

Fig. 30. Mach $=1.69, \mathrm{Re}_{\mathrm{ft}}=3.49$ million/ft with 2-D forward-facing steps.

\section{Copyright Statement}

This material is declared a work of the U.S. Government and is not subject to copyright protection in the United States. 